\author{
Universidade de São Paulo \\ Instituto de Física de São Carlos \\ Departamento de Física de São Carlos e Ciência dos Materiais
}

\author{
Jader de Souza Cabral
}

\title{
Ressonâncias moleculares em átomos de Rydberg frios.
}

São Carlos

Fevereiro - 2009 


\section{Jader de Souza Cabral}

\section{Ressonâncias moleculares em átomos de Rydberg frios}

Dissertação apresentada ao Programa de Pós-Graduação em Física do Instituto de Física de São Carlos da Universidade de São Paulo, para obtenção do título de Mestre em Ciências.

Área de concentração: Física Básica.

Orientador: Prof. Dr. Luis Gustavo Marcassa.

São Carlos - SP

Fevereiro de 2009 
AUTORIZO A REPRODUÇÃO E DIVULGAÇÃO TOTAL OU PARCIAL DESTE TRABALHO, POR QUALQUER MEIO CONVENCIONAL OU ELETRÔNICO, PARA FINS DE ESTUDO E PESQUISA, DESDE QUE CITADA A FONTE.

Ficha catalográfica elaborada pelo Serviço de Biblioteca e Informação IFSC/USP

Cabral, Jader Souza

Ressonâncias moleculares em átomos de Rydberg frios./Jader Souza Cabral; orientador Luis Gustavo Marcassa-- São Carlos, 2009.

$69 \mathrm{p}$.

Dissertação (Mestrado - Programa de Pós-Graduação em Física - Área de concentração: Física Básica ) - Instituto de Física de São Carlos da Universidade de São Paulo.

1. Átomos de Rydberg frios. 2. Ressonâncias moleculares. 3. Transferência de população. .4. Estados nD. I. Título. 


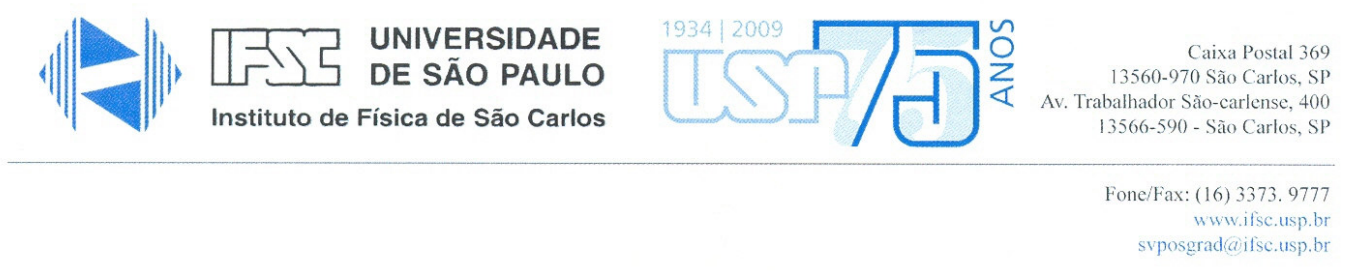

\title{
FOLHA DE APROVAÇÃO
}

Jader de Souza Cabral

Dissertação apresentada ao Instituto de Física de São Carlos da Universidade de São Paulo para obtenção do título de Mestre em Ciências. Área de Concentração: Física Básica.

Aprovado em: 16/02/2009

\section{Comissão Julgadora}

Prof. Dr. Luis Gustavo Marcassa Instituição: IFSC/USP

\author{
Assinatura
}

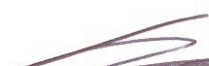

Prof. Dr. Cleber Renato Mendoça Instituição: IFSC/USP Assinatura Clebre Renata Mendana

Prof. Dr. Andre Luiz de Oliveira Instituição: UDESC Assinatura

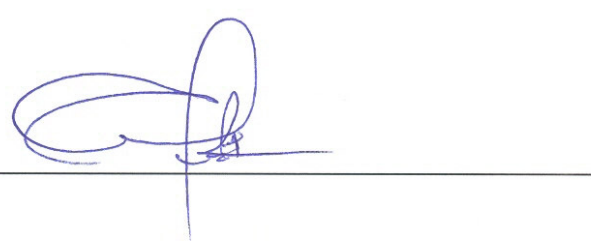


Aos meu pais, Amarildo e Rosana. 


\section{Agradecimentos}

Ao Prof. Luis Gustavo Marcassa meus sinceros agradecimentos pela orientação deste trabalho, assim como sua confiança e dedicação incansável.

À todos meus professores de graduação e pós graduação pela base científica fundamental para conclusão desse mestrado. O básico bem aprendido nos capacita para tentarmos o novo.

Aos meus amigos e companheiros de laboratório Bruno Marangoni e Renato Menegatti pela ajuda nos experimentos, discussões científicas e momentos de descontração.

Aos meus pais, Amarildo e Rosana. Não sei como demonstrar o amor que sinto por vocês. Muito obrigado pelo carinho e, principalmente, pelo apoio incondicional que vocês sempre me deram.

À minha namorada Rita pela paciêcia e compreensão nos momentos mais difícies.

Aos meus grandes amigos Rafael(Kasão), Luis Guilherme(Militar), Buno(Magda), Marcão, Filipão, João Henrique, Gustavo, Rafael(Borga), Giovanni(Botini). Sem vocês o caminho teria sido bem mais árduo.

Ao meu mais novo e querido amigo, Alexandre(Tattinho). Alguém como você não se conhece em qualquer esquina(ou tatame). Não tenho palavras para agradecer todo o apoio e carinho que você me deu. Sem contar o aprendizado.

À todas as pessoas que passaram por vida deixando algo de bom. Seria muitos nomes para escrever e com certeza injustiças seriam cometidas por minha memória.

À equipe da oficina mecânica, sempre prestativos e criteriosos no que fazem.

Às secretárias Isabel, Bene, e as bibliotecárias Neusa, Maria Cristina e Betânia que tornam nossa caminhada mais fácil.

À FAPESP, pelo apoio financeiro. 
“"”Não se pode ensinar alguma coisa a alguém, pode-se apenas auxiliar a descobrir por si mesmo."

Galileu Galilei 


\section{Resumo}

CABRAL, J. S. Ressonâncias moleculares em átomos de Rydberg frios. 2009. 68p. Dissertação (Mestrado)- Instituto de Física de São Carlos, Universidade de São Paulo, São Carlos, 2009.

O entendimento das interações de ultralongo alcance envolvendo átomos de Ryberg frios é o ponto principal para o uso deste sistema em computação quântica. Neste trabalho estudamos tais interações envolvendo estados $\mathrm{nD}+\mathrm{nD}$ em um novo aparato experimental, o qual permite o controle de campo elétrico de uma forma mais eficiente. Mais especificamente estudamos o processo colisional $n D+n D \rightarrow(n+2) P+(n-2) F$ na presença de campo elétrico estático fixo. Este processo é importante porque pode levar a decoerência da amostra. Os resultados obtidos indicam a existência de uma ressonância molecular que é sensível ao efeito Stark. Além disso, investigamos se o movimento atômico é importante para popular tais estados. Por fim, proporemos novos experimentos que podem ser úteis para controlar e suprimir tais processos colisionais e assim permitir avanços na área de computação quântica com tais sistemas.

Palavras-chave: Átomos de Ryderd frios. Ressonâncias moleculares. Transferência de população. Estados $\mathrm{nD}$. 


\section{Abstract}

CABRAL, J. S. Molecular ressonances in cold Rydberg atoms. 2009. 68p. Dissertation (Master program)- Instituto de Física de São Carlos, Universidade de São Paulo, São Carlos, 2009.

The understanding of ultralong-range interaction involving cold Rydberg atoms is the main step for use this system in quantum computation. In this work, we have studied interaction involving $n D$ states in a new experimental setup, which allows us to control the electric field in a more efficient way. More specifically, we have studied the collision process $n D+n D \rightarrow(n+2) P+(n-2) F$ in the presence of a static electric field. This process is important because it can lead to a decoherence of the sample. The observed results show the existence of a molecular resonance which is dependent of Stark effect. Moreover, the atomic motion is perhaps also important to populate such states. Finally, we propose new experiments that can be useful to control and to suppress theses colisional processes and in this way allows us to move on in quantum computing area with such systems.

Key-words: Cold Rtdberg atoms. Molecular ressonances. Population transfer. nD states. 


\section{Lista de Tabelas}

Tabela 2.1 - Estados moleculares para diferentes simetrias de acordo com (38). . . . 27

Tabela 2.2 - Valores números de coeficientes de dispersão para $R b$ - Rb calculados por (38). . . . . . . . . . . . . . . . 28 


\section{Lista de Figuras}

Figura 2.1 - (a) Notação usada para potenciais moleculares no caso homonuclear;

(b) Eixos de simetria do par atômico separados por R. . . . . . . . . . 23

Figura 2.2 - Curvas de potenciais de longo alcance calculada para o Rb-Rb próximos de 30D + 30D considerando apenas a interação de dipolo . . . . . . .

Figura 2.3 - Observação de ressonância molecular publicado em (33). Note que o pico de colisão corresponde a ressonância molecular calculada usando a bordagem descrita nesta secção.

Figura 3.1 - (a) Desenho da nova câmara; (b)Foto da nova câmara com o sistema de vácuo (bombeamento) e bobinas de campo. . . . . . . . . . . . . .

Figura 3.2 - O laser pulsado excita para estados de Rydberg, com $n$ da ordem de $30-40 \ldots \ldots \ldots \ldots 37$

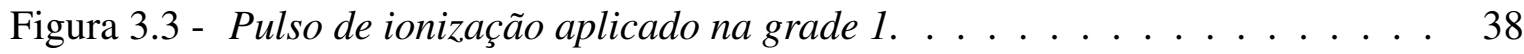

Figura 3.4 - (a) Esquema do pulso de HV aplicado na grade 1; (b) Foto do interior da câmara mostrando o sistema de detecção e o dispenser. . . . . . . . .

Figura 3.5 - Esquema da seqüência temporal do experimento para produção e detecção dos estados de Rydberg. . . . . . . . . . . . . . . . . . . . . . . 40

Figura 3.6 - Espectro típico obtido em nossas medidas. . . . . . . . . . . . . . . . . 41

Figura 3.7 - Fluxograma representando o sistema de detecção e de aquisição de dados. 42

Figura 3.8 - População de $42 \mathrm{P}$ em função do campo total presenciado pelos átomos da armadilha. O campo elétrico residual é da ordem de $1.5 \mathrm{~V} / \mathrm{cm} . \quad$. . . 43

Figura 4.1 - Típico sinal de elétrons obtido na excitação de um estado nD. . . . . . . 45

Figura 4.2 - População em (n+2)P em função de $n D$ para (a) $E=0 \mathrm{~V} / \mathrm{cm}$ e (b) $E=$ $1 \mathrm{~V} / \mathrm{cm}$. A linha é um ajuste utilizando $\rho_{n D}^{s}$, onde $s=1,8 \pm 0,1 \ldots \ldots$.

Figura 4.3 - Comportamento de $K$ em função de $n$ para diferentes campos elétricos estáticos. $O$ intervalo de tempo entre excitação e detecção era de $\Delta t=$

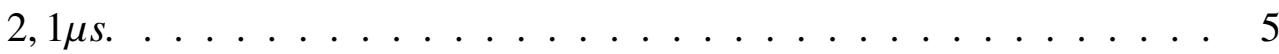

Figura 4.4 - População em 39P em função do campo elétrico estático quando o estado 37D era excitado.

Figura 4.5 - Mapa Stark calculado pelo Prof. Shaffer da Universidade de Oklahoma. As regiões indicadas apresentam colisões ressonantes. . . . . . . . . . 52

Figura 4.6 - População em 39P em função do tempo entre excitação e detecção. . . . 54 
Figura 4.7 - Comportamento de K em função de $n$ para diferentes campos elétricos estáticos. $O$ intervalo de tempo entre excitação e detecção era de $\Delta t=$ $100 n s . \ldots \ldots \ldots \ldots \ldots$

Figura 4.8 - (a) Potencial $32 S+32 S$ e estados próximos para $M=1$ e um campo elétrico $D C$ de $500 \mathrm{mV} / \mathrm{cm}$. O Potencial para $32 P+31 P$ é energicamente abaixo do $32 S+32 S$ para todos os $R ;(b) C(R)=\langle n S+n S \mid n P+(n-1) P\rangle .58$

Figura 4.9 - Sinal de elétrons resolvido no tempo mostrando os estados $32 P$ e 32S. . 60 


\section{Sumário}

1 Introdução 14

2 Potenciais de Ultralongo Alcance entre Átomos de Rydberg $\quad 22$

2.1 Nomenclatura e Simetrias de Potenciais Moleculares . . . . . . . . . . . . 23

2.2 Cálculo dos Potenciais Usando Método Perturbativo . . . . . . . . . . . . . . 25

2.3 Cálculo Envolvendo Interações de Maior Ordem e Efeito Stark de Potenciais de Ultralongo Alcance . . . . . . . . . . . . . . . . . . . . . 29

3 Montagem e Procedimento Experimental 33

3.1 Sistema Óptico de Aprisionamento . . . . . . . . . . . . . . . . 33

3.2 Nova Câmara de Aprisionamento . . . . . . . . . . . . . . . . . 34

3.3 Sistema de Produção e Detecção de átomos de Rydberg . . . . . . . . . . . . . 36

3.4 Sequência Experimental e Sistema de Aquisição . . . . . . . . . . . . . . . . . 40

3.5 Calibração do Campo Elétrico Residual . . . . . . . . . . . . . . . . . 42

4 Resultados e Discussões $\quad 44$

4.1 Observação da Transferência de População . . . . . . . . . . . . . . . . . . 45

4.2 Caracterização do Processo de Transferência em Função do Número Quântico Principal e do Campo Elétrico Es-

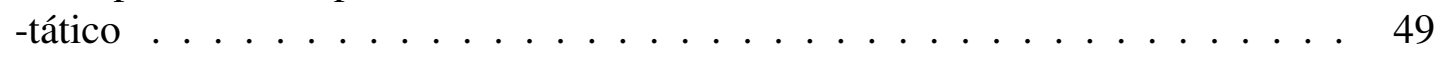

4.3 Evolução Temporal da Transferência de População . . . . . . . . . . . . . . 53

5 Conclusões $\quad 63$

$\begin{array}{ll}\text { Referências } & 67\end{array}$ 


\section{$1 \quad$ Introdução}

A busca pelo conhecimento da estrutura da matéria teve sua origem na Grécia Antiga, no século IV a.C., com dois nomes bastante conhecidos na filosofa pré-socrática, que são Leucipo de Mileto e Demócrito de Abdera. Ambos são considerados os maiores expoentes da teoria do atomismo, que diz que a estrutura da matéria é formada por partículas indivisíveis, os "átomos" em grego. A Atomística se desenvolveu até o final do período romano em torno do século IV, sendo abandonada. A partir daí dominou a teoria de Aristóteles que envolvia 4 elementos básicos.

Em meados do século XIX John Dalton, cientista inglês, publicou um extenso trabalho a respeito da teoria atômica, onde apresenta pela primeira vez a Lei das Proporções. É neste instante que a Atomística começa a atrair a atenção de cientista que começaram a testa - la experimentalmente com técnicas cada vez mais avançadas. A partir daí, outros nomes conhecidos da comunidade científica não mediram esforços pra construir uma teoria atômica sólida, com bases científicas compreendidas por todos.

Podemos citar aqui alguns nomes de cientistas do século XIX e XX que contribuíram para a evolução da teoria. Joseph John Thomson, descobridor do elétron em 1896, evoluiu da idéia do século XIX que a matéria era formada por partes indivisíveis para o conceito de partículas subâtomicas com polarizibilidade oposta. Baseado em seus resultados, Thomson propôs a teoria de pudim com ameixas. Também no início do século XX Ernest Rutherford, com sua famosa 
experiência de emissão de partículas $\alpha$ sobre uma placa fina de ouro, constatou a não homogeneidade dos átomos, e o conceito de núcleo atômico e nuvem eletrônica se fundamentou pela primeira vez.

A partir de meados da segunda década do século XX a história da teoria atômica começa a se fundir com a história do advento da teoria quântica. Os avanços trazidos por Niels Bohr, Max Planck, Werner Heisenberg, Erwin Schrödinger, Albert Einstein entre outros possibilitaram uma investigação mais precisa sobre a natureza atômica. Desvendando em detalhes a natureza quântica da matéria.

O modelo atômico clássico que conhecemos nos dias atuais foi proposto por Niels Bohr no começo do século XX. Na tentativa de unificar os resultados experimentais de Rutherford com a mecânica quântica de Max Planck, Niels Bohr propõe o modelo conhecido como semi-clássico, o chamado modelo planetário para o átomo.

O átomo planetário, ou átomo de Bohr, é caracterizado por duas regiões: a) o núcleo central denso e estático formado por cargas positivas, os prótons, e cargas neutras, os nêutrons, e b) uma densidade eletrônica de cargas negativas, os elétrons, que orbitam ao redor do núcelo em movimento circular com níveis de energia bem definidos. Na mudança de órbita e consequentemente mudança de energia do átomo, pacotes discretos de energia, chamados quanta, são absorvidos ou emitidos pelo elétron.

Tal modelo apesar de ser um tanto contraditório, pois tenta unificar os fundamentos da mecânica clássica e eletromagnetismo com a teoria quântica, se mostrou muito útl para descrever os elemetos químicos e concorda muito bem com experimentos de investigação da estrutura atômica.

As técnicas de investigação da estrutura da matéria também sofreram uma evolução não 
menos interessante que a da própria história da estrutura atômica. Uma das principais é a espectroscopia, onde a luz é usada como agente investigador da natureza atômica. Os primeiros espectros observados são datados de 1814, quando o físico alemão Joseph Von Fraunhofer construiu uma rede de difração e observou as linhas espectrais do sol. É importante citarmos também trabalhos datados do final do século XIX realizado por Johann Jakob Balmer e Rydberg que contribuíram para o avanço da espectroscopia e para a evolução da teoria quântica.

Outro fato importante na história da estrutura atômica foi a descoberta que a luz exercia força sobre a matéria , as Ref. $(1,2)$ apresenta uma boa abordagem histórica. Contudo, sua aplicação prática só foi possível com o advento de fontes de luz laser. Assim, experimentos mais modernos no início da década de 80 possibilitaram um entendimento bem melhor da estrutura atômica e seu caráter quântico.Uma das técnicas modernas utilizadas para a investigação do átomo é a de esfriamento e aprisionamento atômico por lasers em conjunto com campos magnéticos estáticos. O primeiro aprisionamento magneto-óptico foi realizado por E. L. Raab e colaboradores (3) em 1985, que rendeu o Prêmio Nobel de Física em 1997.

Atualmente a armadilha magneto óptica (AMO) é a mais simples usada, a qual envolve campo magnético estático e eletromagnético ressonante. Esta combinação permite criar um ambiente que refrigera e aprisiona átomos cujas velocidades iniciais sejam da ordem de $1 K$. Com isso, é possível obter amostras atômicas à temperatura da ordem de centenas de $\mu K$, densidades entre $10^{10}$ e $10^{12}$ átomos $/ \mathrm{cm}^{3}$ e um total de átomos aprisionados entre $10^{6}$ e $10^{9}$.

Este tipo de armadilha foi fundamental para o desenvolvimento da área de Física Atômica nos últimos vinte anos, permitindo o estudo de colisões atômica em um regime de temperatura até então inédito (4); metrologia de tempo e freqüência com alta precisão $(5,6)$; obtenção de moléculas no estado eletrônico fundamental $(7,8)$; e a obtenção da condensação de BoseEinstein (9-11). Maiores detalhes do funcionamento da Armadilha Magneto-Óptica (AMO) 
bem como os cálculos da força de pressão de radiação podem ser encontrados em $(4,12)$.

Com esse aparato experimental poderoso e com lasers cada vez mais sintonizáveis, o estudo de átomos de Rydberg frios despertou o interesse de muitos grupos de física atômica no mundo. Esses átomos apresentam um número quântico principal $n$ elevado, sendo comumente chamados de "átomos gigantescos", podendo ter um raio médio de milhares de raios de $\operatorname{Bohr}\left(a_{0}\right)$ e possuem características exacerbadas. Entre elas podemos ressaltar o tempo de vida de estados de Rydberg, os quais são da ordem de micro-segundo, podendo chegar a ultrapassar o valor de $1 m s$ (13). Isto possibilita estudos de colisões (14-16), transferência de energia (17-19), medida de tempo de vida $(15,20)$, ressonâncias $(21)$, bloqueio ótico de excitação $(22)$, plasmas $(23,24)$ e até astrofísica (25).

Nos últimos anos, átomos de Rydberg frios têm sido propostos como excelentes candidatos no estudo de computação quântica $(26,27)$. Isto se deve ao fato destes átomos apresentarem interações de ultralongo alcance, em geral na faixa de 5 à $10 \mu m$ para um número quântico principal variando entre 30 e 70 . Fazendo uso de tal interação, várias propostas teóricas utilizam os estados internos destes átomos para gerar o emaranhamento, e assim criar o bit quântico, o chamado "qubit".

Entretanto, essas mesmas interações de ultralongo alcance podem levar a ocorrência de novos fenômenos físicos como, por exemplo, colisões $(14,15,28)$, transferência de energia num gás congelado (17-19) e formação de plasmas $(23,24)$ que causam decoerência no sistema, destruindo assim o "qubit". Já existem propostas para separarem tais átomos espacialmente reduzindo assim efeitos de perda de coerência (29).

Tanto as colisões quanto a transferência de energia num gás congelado precisam ser bem compreendidas antes que possamos evoluir com a aplicação de átomos de Rydberg em um 
computador quântico. Atualmente duas interpretações a respeito da natureza desses efeitos são plausíveis. A primeira é fundamentada no movimento atômico, dois átomos de Rydberg sentem o potencial atrativo iniciando o movimento até atingirem a região de colisão. Nesta região de curto alcance os potenciais se cruzam, e os átomos saem da colisão em um estado diferente do inicial, com ganho de energia cinética. Overstreet e colaboradores mediram tal ganho de energia cinética em uma amostra de átomos de Rydberg frios de $C s$ (30). Tais resultados concodaram muito bem com a simulação. Ou seja, trata-se de um processo de dois corpos.

Esta interpretação tem sido utilizada $(14,15)$ tanto para explicar nossos resultados, quanto os resultados que são atribuídos a transferência de energia. Em trabalho publicado, Nascimento e colaboradores (16) mostram que os resultados apresentados por Li e colaboração em (31) concordavam muito bem com modelo de colisão por dois corpos proposto por nosso grupo em (14).

A segunda interpretação é fundamentada na ausência de movimento dos átomos de Rydberg frios, ou seja, apenas na transferência da energia. O gás se comporta com se estivesse congelado, estático, e a interação ocorre por transferência de energia via muitos corpos $(18,19)$. Mourachko e colaboradores estudando átomos de $C s$ frios no estado de Rydberg, à $100 \mu K$, com densidade de $10^{8}$ a $10^{10} \mathrm{~cm}^{-3}$ propôs tal interpretação (17).

Esta interpretação também foi proposta por Anderson e colaboradores (32), acrescentando que essas colisões ressonantes dipolo-dipolo dependem da temperatura. Em regime de altas temperaturas, $300 K$, a colisão ocorre via dois corpos, e em regime de baixas temperaturas, $300 \mu K$, a interação é via muitos corpos.

Nosso grupo vem estudando nos últimos anos processos colisionais envolvendo átomos de $R b$ frios no estado de Rydberg. E bons resultados já foram apresentados que corroboram a 
interpretação de movimento atômico sob ação de potencial atrativo e colisão via dois corpos $(14,15)$. Recentemente nosso grupo se dedicou a experimentos envolvendo campos elétricos estáticos e estudo do efeito Stark DC na amostra.

Utilizando uma AMO padrão com átomos de $R b$ frios no estado de Rydberg, com $n$ variando entre 30-70, num regime de temperatura de $250 \mu \mathrm{K}$ com densidade atômica de $10^{10}$ átmomos $/ \mathrm{cm}^{3}$, Nascimento e colaboradores (2) realizaram medidas de dependência de população em estados nS e nD em função do tempo entre excitação e detecção na presença de campos elétricos estáticos fixos. Para tempos da ordem de $4 \mu s$ a população $n P$ proveniente do processo $n S+n S$ $\rightarrow n P+(n-1) P$ e a população de $(n+2) P$ proveniente do processo $n D+n D \rightarrow(n+2) P+(n-2) F$ apresentaram uma dependência quadrática com as populações de $n S$ e $n P$ respectivamente. E para tempos mais longo essa dependência se tornava linear.

Experimentos envolvendo $n D+n D$ também foram realizados por T. Amthor e colaborados (33). Porém, os resultados foram interpretados como sendo devido a interação de muitos corpos. Trabalhando com átomos de Rydberg frios de $R b$ no estado $60 D_{5 / 2}$, T. Amthor e colaboradores chegaram a conclusão que na escala de tempo dos primeiros micro-segundos a colisão ocorre via dois corpo, porém a medida que o tempo evolui o efeito de muitos corpos é dominante. Para ilustrar tal interpretação basta imaginar uma caixa com bolinhas, que são os átomos; a curta distância a colisão é binária, porém a longa distância todas as bolinas devem ser consideradas e a simulação envolve método de Monte Carlo.

Contudo, em nosso caso, o efeito foi interpretado como colisão via dois corpos até $4 \mu s$; e para tempos longos o efeito da transferência devido a radiação de corpo negro era dominante. Assim, conseguíamos explicar o comportamento quadrático para curtos tempos e linear para grandes tempos. Isto funciona muito bem para o caso do $n D+n D$, visto que tais estados apresentam potenciais atrativos que cruzam com os do $(n+2) P+(n-2) F$ a curto alcance. 
Porém, os estados $n S+n S$ são repulsivos e esta interpretação fica comprometida.

Na tentativa de explicar nossos resultados buscamos colaboração com o grupo do Prof. J. Shaffer, da Universidade de Oklahoma. Em trabalhos anteriores o grupo liderado por Shaffer mostrou com átomos de Rydberg frios de $C s$ o aparecimento de ressonâncias moleculares (30). Essa colaboração possibilitou o entendimento dos resultados do experimento envolvendo $n S+$ $n S$. O cálculo das curvas de potenciais, levando em conta a interação com campo elétrico e a interação fina, mostrou o aparecimento de ressonâncias moleculares. Tais cálculos concordavam muito bem com dados experimentais de nosso grupo (34).

Deste trabalho em conjunto surgiu a proposta de que talvez este mecanismo estivesse presente no caso $n D+n D$. Essa foi nossa motivação para retomar os estudos de processos colisionais na presença de campo elétrico estático porém agora um sistema experimental novo, mais robusto que nos permitiu um melhor controle do campo elétrico na amostra.

O objetivo deste trabalho de dissertação de mestrado é a construção de um novo aparato experimental que nos permita estudar processos colisionais na presença de campo elétrico estático, com um eficiente controle de campo na amostra de $R b$ frio aprisionado numa AMO. Em particular, estudaremos o seguinte processo colisional $n D+n D \rightarrow(n+2) P+(n-2) F$ a fim de entendermos melhor a interação de ultralongo alcance presente nos átomos de Rydberg.

Analisando a população em $(n+2) P$ resultante do processo $n D+n D \rightarrow(n+2) P+(n-$ 2)F para tempos muito curtos, entre excitação e detecção da ordem de 100ns, ressonâncias moleculares foram observadas. Ou seja, para curtas distâncias internucleares o par $n D+n D$ possui um caráter $(n+2) P+(n-2) F$, o qual permite sua excitação direta pelo laser. Para tempos maiores, observamos uma dependência temporal da população em $(n+2) P$. Até o momento a interpretação devido ao movimento não pode ser descartada; porém o mecanismo 
ainda não está claro.

No Capítulo 2 fazemos uma abordagem teórica qualitativa dos potenciais de ultralongo alcance presente nas interações entre átomos de Rydberg. Discutiremos os princípios básico de como diagonalizar o hamiltoniano do sistema, levando em consideração termos de efeito Stark DC e AC e interação de estrutura fina. A implementação destes cálculos, contudo, não é uma tarefa fácil e requer simulações em super computadores. Por isso é fundamental a colaboração com um grupo como o de Oklahoma.

No Capítulo 3 apresentamos o novo sistema experimental bem como os detalhes dos métodos utilizados em todos os experimentos. Descrevemos em detalhes a varredura em freqüência do laser de excitação, o sistema de ionização, a calibração e controle do campo elétrico presente na amostra e sistema de aquisição de dados.

O Capítulo 4 é reservado para a apresentação e discussões dos resultados obtidos no estudo do processo $n D+n D \rightarrow(n+2) P+(n-2) F$. Mostramos que para tempos da ordem de 100ns ressonâncias moleculares foram observadas. Também observamos que a população no estado $(n+2) P$ apresenta uma evolução temporal, a qual pode ser associada ao movimento molecular em um potencial de ultralongo alcance atrativo. Contudo, isso ainda não foi provado de um modo inequívoco.

Por fim, o Capítulo 5 é destinado às conclusões obtidas deste trabalho, bem como às discussões de futuros experimentos propostos que serão úteis no estudo de interações entre átomos de Rydberg e computação quântica. 


\section{$2 \quad$ Potenciais de Ultralongo Alcance entre Átomos de Rydberg}

Com o avanço das técnicas experimentais, como a de resfriamento e aprisionamento a laser, (3), a produção de altas densidades de átomos de Rydberg em regime de micro-Kelvin se tornou viável em inúmeros laboratórios de física atômica ao redor do mundo $(15,17,18,32)$. Nesse regime, a agitação térmica é tão pequena, que as interações de van-der-Walls não são mascaradas pelo movimento térmico e potencias de ultra longo alcance podem ser importantes em sistemas envolvendo átomos de Rydberg frios.

Essa interação entre átomos de Rydberg frios é responsável por vários fenômenos físicos, de extremo interesse para a física atômica. Como exemplos podem ser citados: o aparecimento de ressonâncias moleculares devido a cruzamento evitados (21), controle de processos colisionais (15), alargamento da curva de densidade de população (35), e outros.

Neste capítulo apresentaremos uma breve revisão sobre a notação de potenciais moleculares e suas simetrias. Em seguida, abordaremos o cálculo desses potenciais utilizando teoria de pertubação de primeira e segunda ordem. Na sequiência apresentaremos o cálculo considerando estados degenerados, incluindo interações de mais alta ordem e efeito Stark DC. 


\subsection{Nomenclatura e Simetrias de Potenciais Moleculares}

Antes de discutirmos sobre o cálculo de potenciais moleculares é aconselhável apresentarmos uma breve revisão sobre a notação utilizada para descrevê-los e suas simetrias. Vamos considerar o caso do par atômico ser formado por dois átomos idênticos, ou seja, caso de moléculas homonucleares, uma vez que trabalhamos apenas com amostra de Rubídio. A figuras 2.1 apresenta a notação utilizada e os eixos de simetria do par.

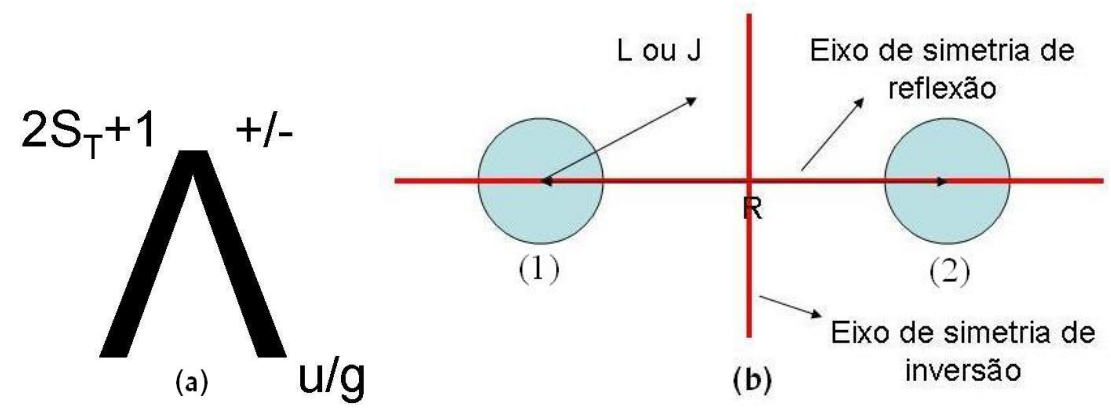

Figura 2.1 - (a) Notação usada para potenciais moleculares no caso homonuclear; (b) Eixos de simetria do par atômico separados por $R$.

A letra grega $\Lambda$, da figura 2.1(a), nos diz qual é a soma da projeção do momento angular total ao longo do eixo molecular. Por exemplo, se o par for constituído por dois átomos no estado $\mathrm{S}$ só teremos $\Lambda=0$ o que corresponde a letra $\Sigma$; se o par estiver em $n P$ podemos ter $\Lambda=0,1$ ou 2 correspondendo à $\Sigma, \Pi$ e $\Delta$ respectivamente.

O termo que aparece no canto superior esquerdo nos diz qual é a degenerescência de spin total, ou seja, se for um singleto o número é 1 e se for um tripleto o número é 3 . Os sinais 
+/- no canto superior direito nos diz a respeito da simetria com relação ao eixo que passa pelo centro dos dois átomos, chamada de simetria de reflexão. O sinal + significa que o par possui tal simetria, já o sinal - nos diz que não possui.

Para finalizar no canto inferior direito temos a letra $g$ ou $u$ que estão ligadas à simetria de inversão, trocar as posições dos elétrons de cada núcleo, ou seja, o elétron que estava próximo ao núcleo 1 é transladado para próximo do núcleo 2 e o elétron que estava próximo ao núcleo 2 é transladado para próximo do núcleo 1, ver figura 2.1(b). A letra $g$ vem de gerade que significa que a função de onda espacial não troca de sinal numa inversão (função par) e o $u$ vem de ungerade que significa que a função de onda espacial troca de sinal numa inversão (função ímpar).

Apresentada a notação desses potenciais, outro ponto relevante a ser abordado é como as operações de simetria nesse par atômico nos fornecem a classificação desses estados e também alguns bons números quânticos.

Como conseqüência de simetria de rotação temos a conservação da projeção do momento angular $M=m_{1}+m_{2}$ no eixo molecular. Quando $M \neq 0$ operações de reflexão mudam o sinal de $M$, porém essa troca de sinal, antrissimetrização de $M$, não muda a energia do estado agora refletido, ou seja, não ocorre quebra de degenerescência entre estados com mesmo valor absoluto de $M$. Por outro lado em estados $\Sigma, M=0$, ocorre mudança de energia na operação de reflexão e estados não degenerados são acessados. Como resultado, operações de simetria de reflexão podem ser usadas para distinguir estados moleculares.

Em operações de simetria de inversão, temos que o produto de duas operações é igual a identidade, $\operatorname{logo}$ a operação deve assumir valor 1 ou -1 . Caso o valor seja 1 , temos o tipo gerade o que implica que os elétrons estão no estado de singleto, que é anti-simétrico; se o 
valor da operação for - 1 temos o tipo ungerade e o estado de tripleto para os elétrons que é simétrico. Isso acontece devido ao Princípio de exclusão de Pauli, que em sua versão mais forte exige que a função de onda total de férmions (caso dos elétrons) seja anti-simétrica.

Conseqüentemente operações de inversão podem levar de estados singletos para estados de tripleto ou vice e versa.

\subsection{Cálculo dos Potenciais Usando Método Perturbativo}

O primeiro artigo teórico a calcular potenciais entre um átomo de Rydberg e um no estado fundamental foi realizado por Greene C. H. (36). Estes potenciais possuem estados ligados conhecidos por Trilobites. Os autores batizaram estes estados assim, porque o quadrado de sua função de onda lembra a forma do animal trilobite, extinto há mais de 300 milhões de anos. Em seguida Christophe Boisseau e colaboradores (37) estenderam estes cálculos para dois átomos de Rydberg no estado $n P$, inclusive calculando estados ligados para estes potenciais. $\mathrm{Na}$ sequência Kilian Singer e colaboradores (38) contribuiram com os cálculos para os potenciais $n S+n S, n P+n P$ e $n D+n D$ para as seguintes combinações de átomos $L i-L i, N a-N a, K-K$, $R b-R b$ e $C s-C s$. Neste mesmo trabalho, foram calculados os coeficientes de dispersão $C_{5}$, $C_{6}, C_{7}, C_{8}$ e $C_{10}$ em função do número quântico principal para $n S+n S, n P+n P, n D+n D$.

Para realizar tais cálculos os autores partiram da interação entre dois átomos separados por uma distância $R$. O potencial pode ser escrito como uma série infinita de potência de $1 / R$, ver Ref. (39), dada pela Eq.(2.1) 


$$
V\left(\vec{r}_{1}, \vec{r}_{2}\right)=-\sum_{n=1}^{\infty} \frac{C_{n}}{R^{n}}=\sum_{l, L=1}^{\infty} \frac{V_{l L}\left(\overrightarrow{r_{1}}, \overrightarrow{r_{2}}\right)}{R^{l+L+1}}
$$

onde $\vec{r}_{1}$ e $\vec{r}_{2}$ são as posições relativas de cada elétron em cada átomo (1 e 2) respectivamente, e $V_{l L}\left(\vec{r}_{1}, \vec{r}_{2}\right)$ é dado pela Eq.(2.2):

$$
V_{l L}\left(\vec{r}_{1}, \vec{r}_{2}\right)=\frac{(-1)^{L} 4 \pi}{\sqrt{(2 l+1)(2 L+1)}} \sum_{m} \sqrt{\left(\begin{array}{l}
l+L \\
l+m
\end{array}\right)\left(\begin{array}{c}
l+L \\
L+m
\end{array}\right)} r_{1}^{l} r_{2}^{L} Y_{l m}\left(\hat{r}_{1}\right) Y_{L-m}\left(\hat{r}_{2}\right)
$$

onde $Y_{l m}(\hat{r})$ são os harmônicos esféricos.Para essas duas equações serem válidas não pode ocorrer sobreposição das funções de onda dos elétrons, logo as interações de troca e de carga entre as funções de onda eletrônica são ignoradas nessa abordagem. Tal situação ocorre para distâncias internucleares maiores que o raio de LeRoy (40), o qual é definido como Eq. (2.3):

$$
R_{L R}=2\left(\left\langle n_{1} l_{1}\left|r^{2}\right| n_{1} l_{1}\right\rangle^{1 / 2}+\left\langle n_{2} l_{2}\left|r^{2}\right| n_{2} l_{2}\right\rangle^{1 / 2}\right)
$$

onde $\left\langle n_{1} l_{1}\left|r^{2}\right| n_{1} l_{1}\right\rangle$ é o elemento de matriz de $r^{2}$ entre as funções de onda radiais pertencentes ao elétron de valência do átomo.

O comportamento dos potenciais entre os átomos em função da distância internuclear é calculado por teoria de perturbação independente do tempo, pois o efeito do termo de $V\left(\vec{r}_{1}, \vec{r}_{2}\right)$ no Hamiltoniano do sistema é muito pequeno se comparado ao efeito dos termos de energia cinética e potencial de cada átomo. uma vez que a dependência é em potência de $1 / R$ e $R$ é da ordem de milhares de raios de Bohr.

Escrevendo o $V\left(\vec{r}_{1}, \vec{r}_{2}\right)$ como uma perturbação do Hamiltoniano do sistema que não inte- 
rage no caso assintótico temos, Eq.(2.4):

$$
H=H_{0}+V\left(\vec{r}_{1}, \vec{r}_{2},\right)=H_{0}+\sum_{l, L=1}^{\infty} \frac{V_{l L}\left(\overrightarrow{r_{1}}, \overrightarrow{r_{2}}\right)}{R^{l+L+1}}
$$

onde $H_{0}$ é o hamiltoniano não perturbado do par atômico.

Antes de aplicarmos a teoria de perturbação de primeira ou segunda ordem devemos escrever as funções de onda dos estados moleculares. Para isso usamos uma combinação linear de orbitais atômicos (CLOA), que se resume basicamente em somar projeções de dois momentos angulares na direção do eixo molecular. Na tabela 2.1 apresentamos os casos $n S+n S$ e $n P+n P$, onde consideramos apenas o momento angular orbital $l$.

Tabela 2.1 - Estados moleculares para diferentes simetrias de acordo com (38).

\begin{tabular}{ccc}
\hline$|\boldsymbol{M}|$ & Simetria Molecular & $\boldsymbol{n} \boldsymbol{S}+\boldsymbol{n S}(\mathbf{C L O A})$ \\
0 & ${ }^{1} \Sigma_{g}^{+},{ }^{3} \Sigma_{u}^{+}$ & $|\mathrm{n} 00, \mathrm{n} 00\rangle$ \\
\hline & & $\boldsymbol{n P}+\boldsymbol{n P}(\mathbf{C L O A})$ \\
\hline $\boldsymbol{M} \mid$ & Simetria Molecular & $|\mathrm{n} 11 \mathrm{n} 11\rangle$ \\
1 & ${ }^{1} \Delta_{g},{ }^{3} \Delta_{u}$ & $\frac{1}{\sqrt{2}}|\mathrm{n} 11, \mathrm{n} 10\rangle-|\mathrm{n} 10, \mathrm{n} 11\rangle$ \\
1 & ${ }^{1} \Pi_{u},{ }^{3} \Pi_{g}$ & $\frac{1}{\sqrt{2}}(|\mathrm{n} 11, \mathrm{n} 10\rangle+|\mathrm{n} 10, \mathrm{n} 11\rangle)$ \\
0 & ${ }^{1} \Pi_{g},{ }^{3} \Pi_{u}$ & $\frac{1}{\sqrt{2}}(|\mathrm{n} 11, \mathrm{n} 1-1\rangle-|\mathrm{n} 1-1, \mathrm{n} 11\rangle)$ \\
0 & ${ }^{1} \Sigma_{u}^{-},{ }^{3} \Sigma_{g}^{-}$ & $\frac{2}{\sqrt{3}}|\mathrm{n} 10, \mathrm{n} 10\rangle+\frac{1}{\sqrt{6}}|\mathrm{n} 11, \mathrm{n} 1-1\rangle+\frac{1}{\sqrt{6}}|\mathrm{n} 1-1, \mathrm{n} 11\rangle$ \\
0 & ${ }^{1} \Sigma_{g}^{+},{ }^{3} \Sigma_{u}^{+}$ & $-\frac{1}{\sqrt{3}}|\mathrm{n} 10, \mathrm{n} 10\rangle+\frac{1}{\sqrt{3}}|\mathrm{n} 11, \mathrm{n} 1-1\rangle+\frac{1}{\sqrt{3}}|\mathrm{n} 1-1, \mathrm{n} 11\rangle$ \\
\hline
\end{tabular}

Usando esses estados moleculares é possível utilizar teoria de perturbação de primeira e segunda ordem para calcular os coeficientes de dispersão $C_{n}$. Para o caso degenerado uma matriz com elementos calculados com primeira ordem de teoria de perturbação é escrita e em seguida 
diagonalizada. Na Referência (41) encontramos os cálculo mais detalhado desses coeficientes e Singer K. apresenta em (38) os seguintes valores para os coeficinetes $C_{5}, C_{6}, C_{7}, C_{8}$ e $C_{10} \mathrm{em}$ função do número quântico principal para $n S+n S, n P+n P, n D+n D$ para os pares $L i-L i$, $N a-N a, K-K, R b-R b$ e $C s-C s$. A tabela 2.2 mostra os resultados de Singer para o par $R b-R b$.

Tabela 2.2 - Valores números de coeficientes de dispersão para $R b$ - Rb calculados por (38).

\begin{tabular}{|c|c|c|c|c|c|c|c|c|c|}
\hline \multirow{3}{*}{$\begin{array}{l}n \mathrm{~s}-n \mathrm{~s} \\
\text { Symmetry } \\
{ }^{1} \Sigma_{\mathrm{g}}^{+},{ }^{3} \Sigma_{u}^{+}\end{array}$} & \multicolumn{3}{|c|}{$C_{6}=n^{11}\left(c_{0}+c_{1} n+c_{2} n^{2}\right)$} & \multicolumn{3}{|c|}{$C_{8}=n^{15}\left(c_{0}+c_{1} n+c_{2} n^{2}\right)$} & \multicolumn{3}{|c|}{$C_{10}=n^{22}\left(c_{0}+c_{1} n+c_{2} n^{2}\right)$} \\
\hline & $\begin{array}{c}c_{0} \\
\left(\times 10^{1}\right)\end{array}$ & $\begin{array}{c}c_{1} \\
\left(\times 10^{-1}\right)\end{array}$ & $\begin{array}{c}c_{2} \\
\left(\times 10^{-3}\right)\end{array}$ & $\begin{array}{c}c_{0} \\
\left(\times 10^{0}\right)\end{array}$ & $\begin{array}{c}c_{1} \\
\left(\times 10^{-1}\right)\end{array}$ & $\begin{array}{c}c_{2} \\
\left(\times 10^{-3}\right)\end{array}$ & $\begin{array}{c}c_{0} \\
\left(\times 10^{-4}\right)\end{array}$ & $\begin{array}{c}c_{1} \\
\left(\times 10^{-6}\right)\end{array}$ & $\begin{array}{c}c_{2} \\
\left(\times 10^{-9}\right)\end{array}$ \\
\hline & 1.197 & -8.486 & 3.385 & -7.303 & 8.068 & -3.792 & -5.546 & 5.242 & -3.154 \\
\hline$n \mathrm{p}-n \mathrm{p}$ & \multicolumn{3}{|c|}{$C_{5}=n^{8}\left(c_{0}+c_{1} n+c_{2} n^{2}\right)$} & \multicolumn{3}{|c|}{$C_{6}=n^{11}\left(c_{0}+c_{1} n+c_{2} n^{2}\right)$} & \multicolumn{3}{|c|}{$C_{8}=n^{15}\left(c_{0}+c_{1} n+c_{2} n^{2}\right)$} \\
\hline Symmetry & $\begin{array}{c}c_{0} \\
\left(\times 10^{9}\right)\end{array}$ & $\begin{array}{c}c_{1} \\
\left(\times 10^{-2}\right)\end{array}$ & $\begin{array}{c}c_{2} \\
\left(\times 10^{-2}\right)\end{array}$ & $\begin{array}{c}c_{0} \\
\left(\times 10^{-1}\right)\end{array}$ & $\begin{array}{c}c_{1} \\
\left(\times 10^{-1}\right)\end{array}$ & $\begin{array}{c}c_{2} \\
\left(\times 10^{-4}\right)\end{array}$ & $\begin{array}{c}c_{0} \\
\left(\times 10^{1}\right)\end{array}$ & $\begin{array}{c}c_{1} \\
\left(\times 10^{0}\right)\end{array}$ & $\begin{array}{c}c_{2} \\
\left(\times 10^{-2}\right)\end{array}$ \\
\hline${ }^{1} \Delta_{g},{ }^{3} \Delta_{u}$ & -0.231 & -1.976 & 0.010 & 3.620 & -0.579 & 2.778 & 1.199 & -0.624 & 0.250 \\
\hline${ }^{1} \Pi_{u},{ }^{3} \Pi_{g}$ & \multicolumn{3}{|c|}{ Vanishes } & 6.070 & -1.273 & 6.157 & 1.173 & 0.010 & -0.069 \\
\hline${ }^{1} \Pi_{g},{ }^{3} \Pi_{u}$ & 0.922 & 7.903 & -0.041 & 3.575 & -0.183 & 0.816 & 2.973 & -2.281 & 0.990 \\
\hline${ }^{1} \Sigma_{u}^{-},{ }^{3} \Sigma_{g}^{-}$ & \multicolumn{3}{|c|}{ Vanishes } & 2.373 & -0.034 & 0.107 & 2.176 & -1.711 & 0.747 \\
\hline${ }^{1} \Sigma_{g}^{+},{ }^{3} \Sigma_{u}^{+}$ & -1.383 & -11.850 & 0.061 & 43.010 & 3.575 & $-1.714^{a}$ & 5.359 & -3.984 & 1.729 \\
\hline${ }^{1} \Sigma_{g}^{+},{ }^{3} \Sigma_{u}^{+}$ & \multicolumn{3}{|c|}{ Vanishes } & 5.461 & -1.133 & 5.476 & 0.712 & 0.244 & -0.162 \\
\hline$n \mathrm{~d}-n \mathrm{~d}$ & \multicolumn{3}{|c|}{$C_{5}=n^{8}\left(c_{0}+c_{1} n+c_{2} n^{2}\right)$} & \multicolumn{3}{|c|}{$C_{6}=n^{11}\left(c_{0}+c_{1} n+\frac{c_{-1}}{n-n_{0}}\right)$} & \multicolumn{3}{|c|}{$C_{7}=n^{11}\left(c_{0}+c_{1} n+c_{2} n^{2}\right)$} \\
\hline & $\begin{array}{c}c_{0} \\
\left(\times 10^{0}\right)\end{array}$ & $\begin{array}{c}c_{1} \\
\left(\times 10^{-2}\right)\end{array}$ & $\begin{array}{c}c_{2} \\
\left(\times 10^{-4}\right)\end{array}$ & $\begin{array}{c}c_{0} \\
\left(\times 10^{1}\right)\end{array}$ & $\begin{array}{c}c_{1} \\
\left(\times 10^{-2}\right)\end{array}$ & $\begin{array}{r}c_{-1} \\
\left(\times 10^{0}\right)\end{array}$ & $\begin{array}{c}c_{0} \\
\left(\times 10^{1}\right)\end{array}$ & $\begin{array}{c}c_{1} \\
\left(\times 10^{-1}\right)\end{array}$ & $\begin{array}{c}c_{2} \\
\left(\times 10^{-1}\right)\end{array}$ \\
\hline${ }^{1} \Gamma_{g},{ }^{3} \Gamma_{u}$ & -1.445 & -2.731 & 1.477 & 2.603 & 1.454 & 66.310 & 0.235 & 0.920 & -0.487 \\
\hline${ }^{1} \Phi_{\mathrm{u}},{ }^{3} \Phi_{\mathrm{g}}$ & -0.722 & -1.366 & 0.738 & 4.124 & 2.475 & 105.000 & -0.059 & -0.230 & 0.122 \\
\hline${ }^{1} \Phi_{g},{ }^{3} \Phi_{u}$ & 2.167 & 4.097 & -2.215 & 0.643 & -0.273 & 16.570 & -0.99 & -3.911 & 2.069 \\
\hline${ }^{1} \Delta_{\mathrm{u}},{ }^{3} \Delta_{\mathrm{g}}$ & 1.686 & 3.186 & -1.723 & 1.730 & 0.525 & 44.200 & 0.352 & 1.380 & -0.730 \\
\hline 13 & 1.565 & 2.959 & -1.600 & 0.571 & -0.584 & 14.650 & 1.260 & 4.940 & -2.614 \\
\hline${ }^{1} \Delta_{g},{ }^{3} \Delta_{u}$ & -0.722 & -1.366 & 0.738 & 5.157 & 3.032 & 131.200 & 0.031 & 0.121 & -0.064 \\
\hline${ }^{1} \Pi_{u},{ }^{3} \Pi_{g}$ & -1.013 & -1.915 & 1.036 & 5.157 & 2.864 & 131.200 & -0.499 & -1.958 & 1.036 \\
\hline${ }^{1} \Pi_{u},{ }^{3} \Pi_{g}$ & 0.773 & 1.460 & -0.789 & 1.789 & 0.563 & 45.640 & -0.381 & -1.493 & 0.790 \\
\hline${ }^{1} \Pi_{g},{ }^{3} \Pi_{u}$ & 1.191 & 2.250 & -1.217 & 2.217 & 0.916 & 56.570 & 0.151 & 0.594 & -0.314 \\
\hline${ }^{1} \Pi_{g},{ }^{3} \Pi_{u}$ & -0.950 & -1.795 & 0.971 & 0.907 & -0.779 & 22.990 & -0.093 & -0.364 & 0.193 \\
\hline${ }^{1} \Sigma_{\mathrm{u}}^{-},{ }^{3} \Sigma_{\mathrm{g}}^{-}$ & -2.338 & -4.419 & 2.389 & 0.274 & -0.870 & 6.928 & 0.849 & 3.330 & -1.762 \\
\hline${ }^{1} \Sigma_{u}^{-},{ }^{3} \Sigma_{g}^{-}$ & 0.893 & 1.688 & -0.913 & 2.676 & 1.229 & 68.210 & 0.324 & 1.272 & -0.673 \\
\hline${ }^{1} \Sigma_{\mathrm{g}}^{+},{ }^{3} \Sigma_{u}^{+}$ & -2.748 & -5.195 & 2.809 & 0.298 & -1.100 & 7.455 & 0.264 & 1.037 & -0.548 \\
\hline${ }^{1} \Sigma_{\mathrm{g}}^{+},{ }^{3} \Sigma_{u}^{+}$ & -1.271 & -2.403 & 1.299 & 4.755 & 2.449 & 120.900 & -1.118 & -4.386 & 2.320 \\
\hline${ }^{1} \Sigma_{g}^{+},{ }^{3} \Sigma_{u}^{+}$ & 0.408 & 0.771 & -0.417 & 2.942 & 1.436 & 74.940 & -0.319 & -1.252 & 0.663 \\
\hline
\end{tabular}




\subsection{Cálculo Envolvendo Interações de Maior Ordem e Efeito Stark de Potenciais de Ultralongo Alcance}

Os cálculos apresentados na seção anterior são úteis quando $-C_{n} / R^{n}$ é menor do que a separação energética entre os estados. Quando estes termos passam a ser comparáveis é necessário resolvermos o problema através da diagonalização da matriz. O primeiro cálculo mais simples é se considerarmos apenas a interação dipolar $(l=L=1)$ na Eq. (2.1). Neste caso é relativamente simples montar a matriz e diagonalizá-la. Como exemplo mostramos na figura 2.2 os potenciais próximos aos estados $30 D+30 D$ considerando apenas a interação dipolar.

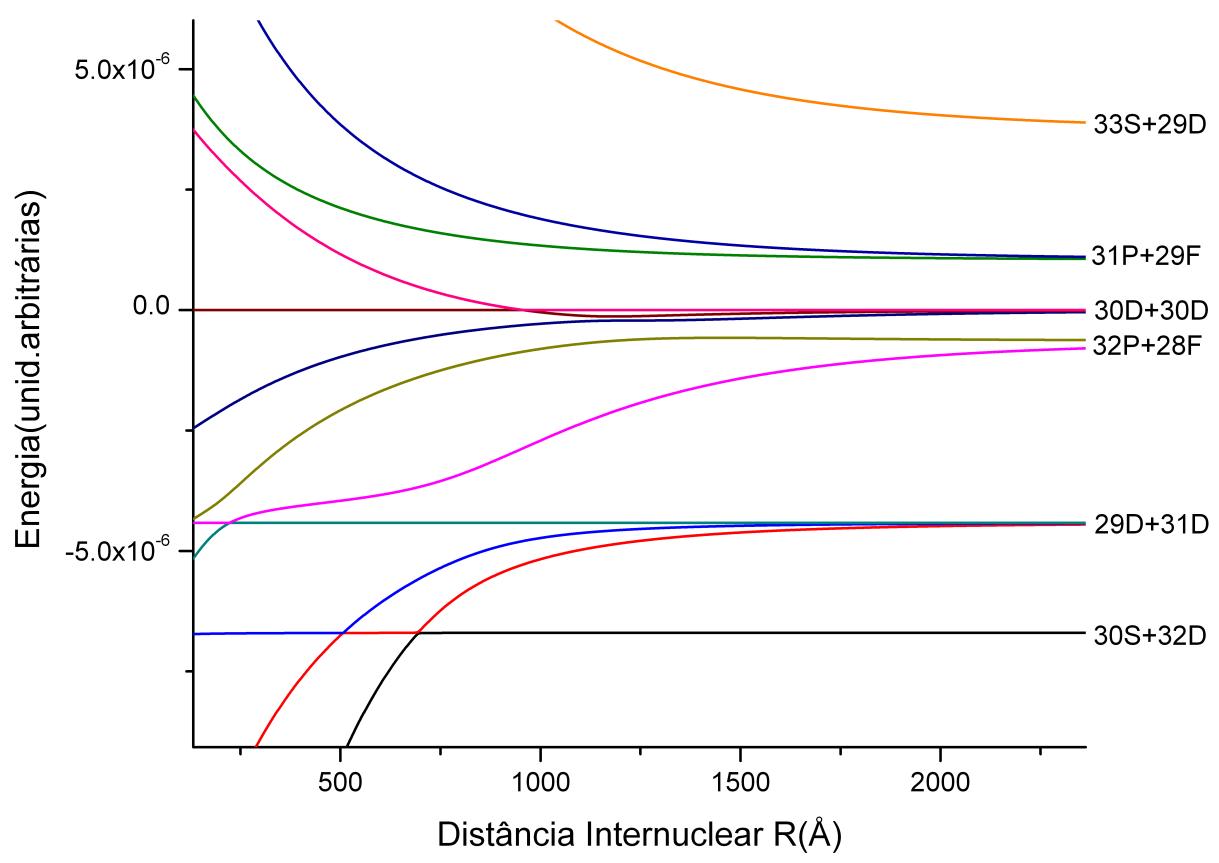

Figura 2.2 - Curvas de potenciais de longo alcance calculada para o Rb-Rb próximos de 30D $+30 D$ considerando apenas a interação de dipolo

Contudo, para compreendermos melhor os efeitos observados no laboratório é necessário incluir interações de mais alta ordem (dipolares, quadrupolares, hexapolares), além de incluir 
estrutura fina e efeito Stark DC. Este tipo de cálculo esta sendo desenvolvido pelo Prof. Shaffer da Universidade de Oklahoma- EUA, com quem estamos em colaboração. Nesta abordagem interações de quadrupólo-dipolo, quadrupólo-quadrupólo, e estrutura fina são levadas em consideração, além do efeito Stark produzido por um campo elétrico DC aplicado ao sistema. Neste caso devemos calcular o seguinte elemento de matriz, Eq. (2.5).

$$
\left\langle\bar{\alpha}\left|\left\langle\bar{\beta}|H(R)| \bar{\alpha}^{\prime}\right\rangle\right| \bar{\beta}^{\prime}\right\rangle=\delta_{\alpha \alpha^{\prime}} \delta_{\beta \beta^{\prime}} E_{\alpha \beta}+\left\langle\bar{\alpha}\left|\left\langle\bar{\beta}\left|H_{D D}(R)+H_{D Q}(R)+H_{Q Q}(R)\right| \bar{\alpha}^{\prime}\right\rangle\right| \bar{\beta}^{\prime}\right\rangle
$$

onde $\alpha$ e $\beta$ representam o conjunto de números quânticos, incluindo a estrutura fina, e $\alpha^{\prime}$ e $\beta^{\prime}$ representam o estado quântico alterado pelo efeito do campo elétrico, efeito Stark.

A distância internuclear $R$ é orientada ao longo do eixo z, que é o mesmo eixo de aplicação do campo elétrico DC. O termo $E_{\alpha \beta}=E_{\alpha}+E_{\beta}$ denota o comportamento assintótico da mudança de energia devido ao efeito Stark, ou seja, é a energia para $R \rightarrow \infty$. Os termos $H_{D D}(R), H_{D Q}(R)$ e $H_{Q Q}(R)$ correspondem respectivamente ao termo de interação dipolo-dipolo, interação dipoloquadrupólo e quadrupólo-quadrupólo.

Primeiramente a mudança de energia devido ao efeito Stark para um único átomo é calculada bem como a base de estados. Em seguida vem a parte mais complexa que é a escolha de uma base, conjunto de estados, para descrever o par atômico, ou seja, base molecular. Por fim é feita a diagonalização da matriz na base onde o efeito Stark foi considerado para o par atômico.É possível também calcular os novos auto vetores que podem ser escritos como na Eq. (2.6):

$$
|\Psi\rangle(R)=\sum C_{\alpha \beta}|\bar{\alpha}\rangle|\bar{\beta}\rangle
$$


onde $C_{\alpha \beta}$ é o coeficiente de expansão da base do par alterado pelo efeito Stark. A escolha da direção do campo elétrico $\vec{E}$ ao longo do eixo que une o par foi feita de modo que possa ser desconsiderada a interação estática dipolar induzida pelo campo.

Recentemente A. Schwettmann e colaboradores (42) utilizaram essa abordagem de cálculo no caso de amostra de átomos de Rydberg frios de Cs. Estudando os níveis de energia em função da distância internuclear na região próxima ao estado $89 D+89 D$ do $C s$ observaram uma mudança no comportamento em tais linhas na presença de diferentes campos elétricos com uma taxa de transferência de energia de $30-70 \mathrm{MHz}$. Nesse mesmo trabalho foi observado a evidência de cruzamentos evitados à distância internuclear da ordem de $5 \mu s$.

No ano seguinte, Overstreet e colaboradores pertencentes ao mesmo grupo publicaram um trabalho experimental (30) onde observaram o aparecimento de ressonâncias moleculares na região próxima ao estado $89 D+89 D$ para o $C$ s. Com um laser contínuo $(\mathrm{CW})$ a amostra de Cs era excitada via dois fótons ressonantes para estado com alto número quântico, da ordem de 89 - 90 na presença de um baixo gradiente de campo próximo a $20 \mathrm{mV} / \mathrm{cm}$. Aumentando a intensidade de excitação, consequentemente aumentando a densidade populacional em $89 D$, eles observaram população numa região próxima aos estados $89 D_{3 / 2}$ e $89 D_{5 / 2}$. Esse sinal de população concorda muito bem com os cálculos téoricos publicados em (42) que correspondem à ressonâncias moleculares. A figura 2.3 mostra a concordância do experimento com o cálculo teórico.

No próximo capítulo apresentaremos nosso sistema experimental bem como as técnicas uilizada na coleta dos dados. 


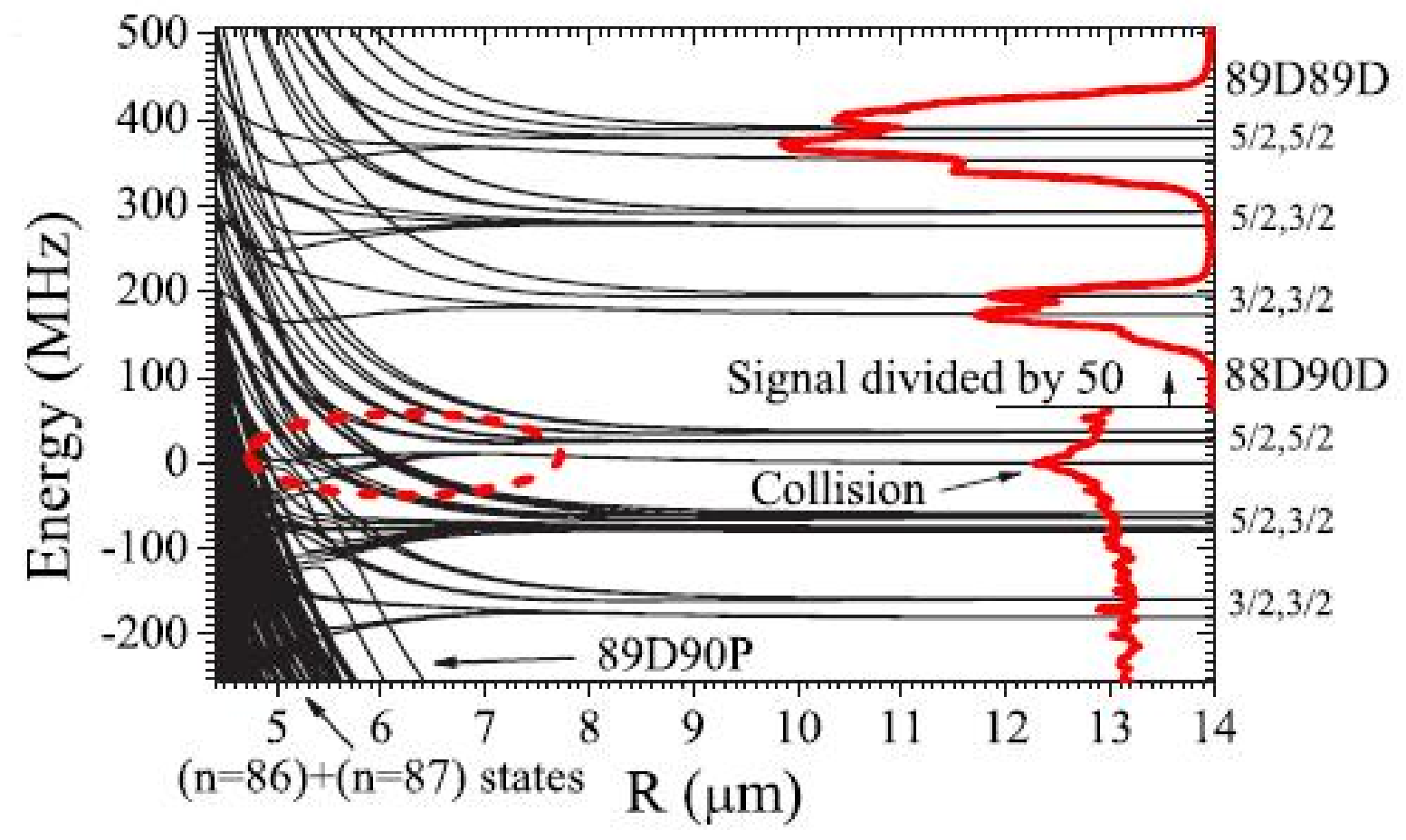

Figura 2.3 - Observação de ressonância molecular publicado em (33). Note que o pico de colisão corresponde a ressonância molecular calculada usando a bordagem descrita nesta secção. 


\section{$3 \quad$ Montagem e Procedimento Experimental}

Neste capítulo apresentamos nosso aparato experimental e as técnicas utilizadas nos experimentos realizados. Começamos descrevendo o sistema óptico da armadilha magneto-óptica, a nova câmara de aprisionamento magnético-óptico bem como a técnica de produção e detecção de átomos de Rydberg. A sequência temporal e o sistema de aquisição de dados dos experimentos são apresentados posteriormente. Por fim descrevemos a técnica utilizada na calibração do campo elétrico residual.

\subsection{Sistema Óptico de Aprisionamento}

Em todos os experimentos realizados utilizamos uma armadilha magneto óptica carregada a partir de um vapor atômico. Os princípios de funcionamento de tal armadilha é conhecido desde a década de $80(3,12)$. Este tipo de armadilha requer o uso de um feixe laser, cuja frequência está próxima de uma transição atômica.

O sistema ótico para resfriamento a laser é constituído por um laser de diodo Sacher Modelo 
Tiger. O laser foi estabilizado em frequência por um sistema integrado de travamento próximo a transição de aprisionamento do ${ }^{85} R b\left|5 S_{1 / 2}, F=3\right\rangle \rightarrow\left|5 P_{3 / 2}, F^{\prime}=4\right\rangle$. A potência média utilizada foi de aproximadamente de $800 \mathrm{~mW}$.

Este feixe laser, contudo, pode realizar uma transição para o estado $\left|5 P_{3 / 2}, F^{\prime}=3\right\rangle$, devido a pequena separação hiperfina entre os estados $\left|5 P_{3 / 2}, F^{\prime}=4\right\rangle$ e $\left|5 P_{3 / 2}, F^{\prime}=3\right\rangle$. Assim, os átomos podem decair espontaneamente para o estado fundamental $\left|5 S_{1 / 2}, F=2\right\rangle$, de modo que não mais interagem com o laser de aprisionamento e deixam de ser resfriados. Portanto, necessitamos de um sistema de rebombeio que coloque os átomos novamente em ressonância com o feixe de aprisionamento. Para isso, utilizamos um modulador eletro-óptico (MEO) que produz uma frequência ressonante com a transição $\left|5 S_{1 / 2}, F=2\right\rangle \rightarrow\left|5 P_{3 / 2}, F^{\prime}=3\right\rangle$. Utilizamos o mesmo laser de bombeio passando focalizado pelo MEO. Através deste modulador podemos controlar a potência do feixe de rebombeio, e assim a população de átomos aprisionados.

\subsection{Nova Câmara de Aprisionamento}

Nossa principal motivação para projetar uma câmara nova foi obtermos maior acesso óptico, ou seja, maior número de janelas. Além disso montarmos um sistema de grades de controle de campo elétrico DC no seu interior mais eficiente. Esse sistema de grades será detalhado na próxima secção.

Essa câmara, feita de aço inox, possui um formato octogonal, onde estão conectados janelas ópticas, detector de íons/eletron e sistema de bombeamento. As tampas superior e inferior 


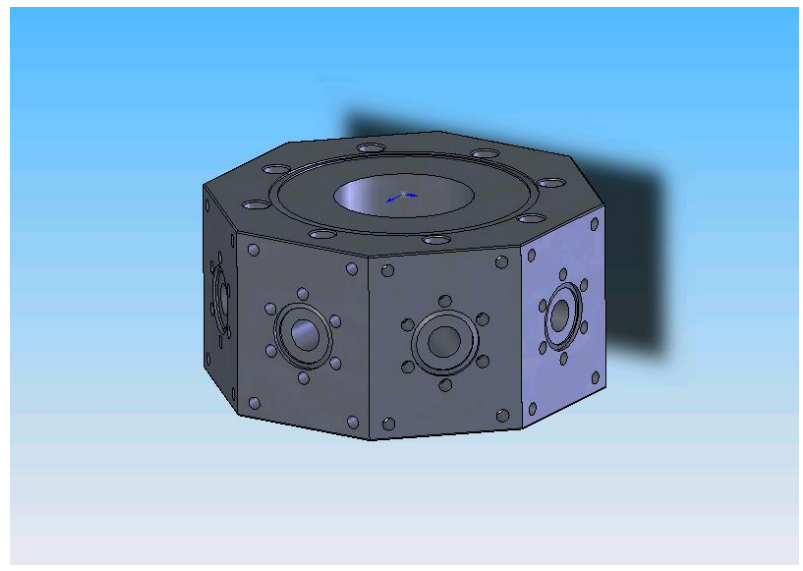

(a)

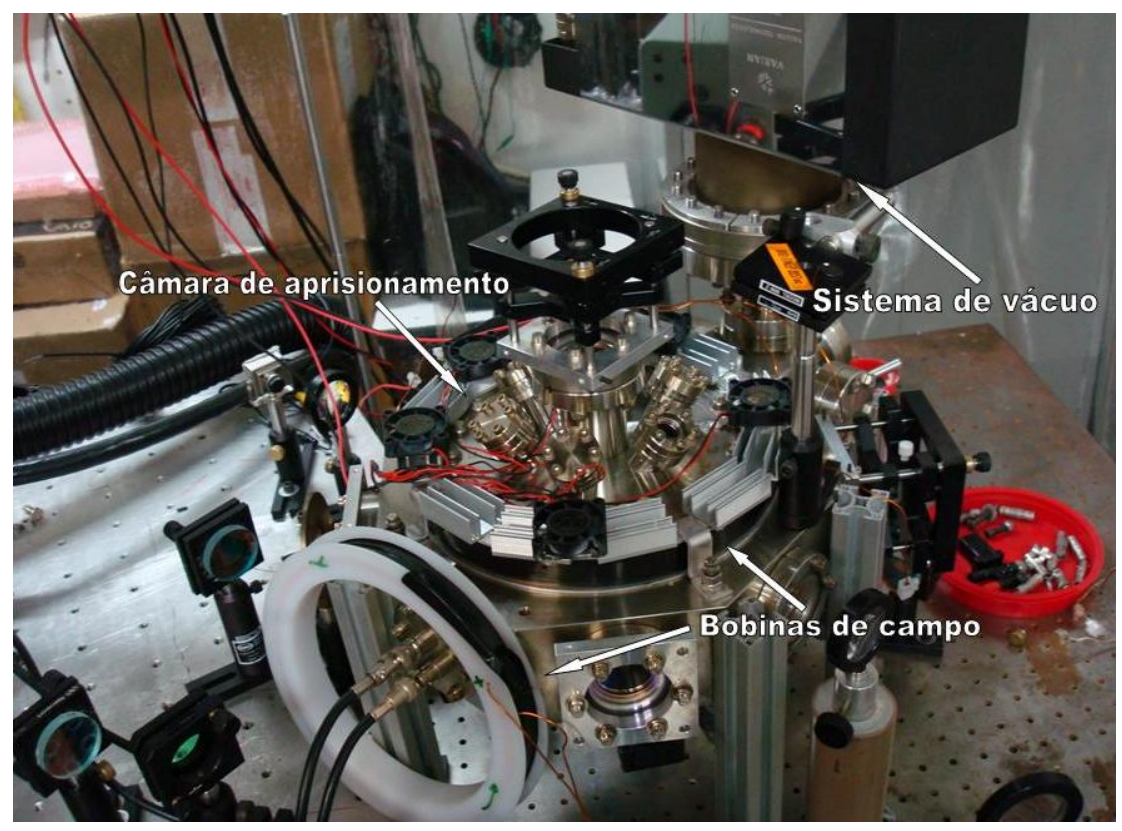

(b)

Figura 3.1 - (a) Desenho da nova câmara; (b)Foto da nova câmara com o sistema de vácuo (bombeamento) e bobinas de campo.

também possuem três acessos ópticos cada uma, tendo a possibilidade de aumentar para seis acessos em cada tampa. A figura 3.1 apresenta o novo sistema de aprisionamento.

Para o sistema de fontes de átomos, foi usado um dispenser. Basicamente trata-se de um sal de $\mathrm{Rb}$ em formato de lâmina, ao qual se aplica uma corrente elétrica contínua de aproximadamente 3,5A. Assim, o sal de $\mathrm{Rb}$ sofre oxi-redução, liberando átomos de $\mathrm{Rb}$ no interior da câmara. Esse dispenser está localizado dentro da câmara, próximo a região central. 
Uma bomba iônica de 55litros/s é responsável por manter uma pressão no interior da câmara da ordem de $10^{-10}$ torr, o que é suficiente para os experimentos a serem realizados. O gradiente de campo magnético, necessário para a armadilha magneto-óptica, é gerado por bobinas na configuração anti- Helmoltz que são presas nas tampas superior e inferior da câmara. O eixo de simetria das bobinas foi alinhado com o eixo vertical da câmara, figura 3.1. As bobinas foram projetadas para uma corrente de aproximadamente $4 A$, de forma a gerar um gradiente de campo magnético de aproximadamente $10 \mathrm{Gauss} / \mathrm{cm}$ na direção vertical. Nos mesmos carretéis foram enroladas duas bobinas na configuração Helmoltz, projetadas para uma corrente de $1 \mathrm{~A}$ de modo a produzirem um campo de 1 Gauss $/ \mathrm{cm}$ na direção vertical. Estas são as chamadas bobinas de compensação e são utilizadas para compensar o campo da bomba iônica.

\subsection{Sistema de Produção e Detecção de átomos de Rydberg}

Uma vez tendo a amostra de átomos frios de $\mathrm{Rb}$ no primeiro estado excitado $\left|5 P_{3 / 2}, F^{\prime}=4\right\rangle$ aprisionada na armadilha, o próximo passo é excitarmos tal amostra para os estados de Rydberg. Essa excitação é feita usando um laser de corante com largura de linha de $0,05 \mathrm{~cm}^{-1}$ (Jaguar Continuum) que é bombeado pelo terceiro harmônico de um laser de Nd:Yag pulsado, também da Continuum. O laser de corante foi preparado para operar na região de 470-485nm. O corante utilizado foi o Exciton Coumarim 480 e o solvente foi o metanol em proporções indicadas pelo fabricante. Cada pulso possui energia aproximadamente de $1 m J$ e são repetidos numa taxa de aproximadamente $20 \mathrm{~Hz}$. 
O feixe pulsado então foi alinhado para atingir a região central da armadilha magnetoóptica, tendo acesso óptico por uma janela na tampa superior da câmara, ou seja, o feixe passa pela diagonal da armadilha magneto-óptica. A figura 3.2 indica no diagrama de níveis do ${ }^{85} R b$ a excitação para os estados de Rydberg.

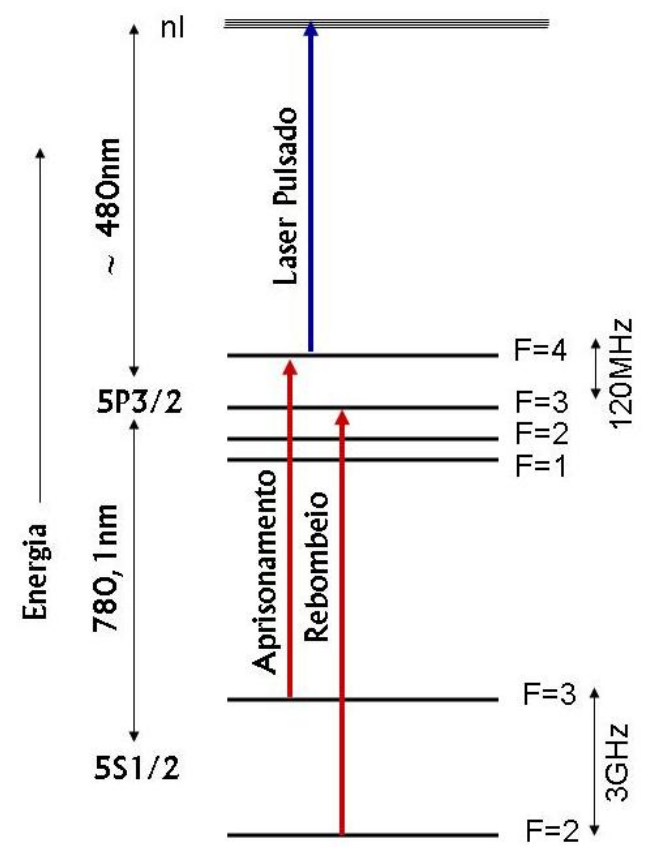

Figura 3.2 - O laser pulsado excita para estados de Rydberg, com n da ordem de $30-40$.

Depois da excitação dos estados de Rydberg é necessário procedermos a detecção. A técnica utilizada por nós é de grande domínio pelo nosso grupo de pesquisa e já vem sendo utilizada a alguns anos $(2,13,15)$. É a chamada ionização por campo pulsado, que consiste em adicionarmos um campo elétrico na amostra, deformando assim o potencial colombiano que confina os elétrons nos átomos. Na presença desse campo o elétron consegue escapar do átomo, ou seja, temos a ionização. Desta forma, podemos detectar tanto o íon quanto o elétron. Devido a melhor resolução, utilizamos a detecção de elétrons neste trabalho.

Com um gerador de pulso AVTECH modelo AVRH 3-OS-PN, com saída de $3 K V$ ligada por dois capacitores em série de 47, $2 n F$ conseguimos um pulso ionizante em forma de rampa, 
figura 3.3. Este pulso foi aplicado na grade 1 do interior da armadilha, figura 3.4. O sistema de grades para ionização é formado por um par de grades metálicas de tamanho $10 \mathrm{x} 7 \mathrm{~mm}$ de transmissão de $95 \%$ separadas por aproximadamente $15 \mathrm{~mm}$, colocadas dentro da câmara. Nessas dimensões o campo produzido é bastante uniforme e a grande transmissividade é para que os feixes laser de aprisionamento possam passar quase sem serem perturbados. O pulso tinha aproximadamente $3 \mu \mathrm{s}$ de duração com amplitude de aproximadamente de $230 \mathrm{~V} / \mathrm{cm}$, figura 3.3 .

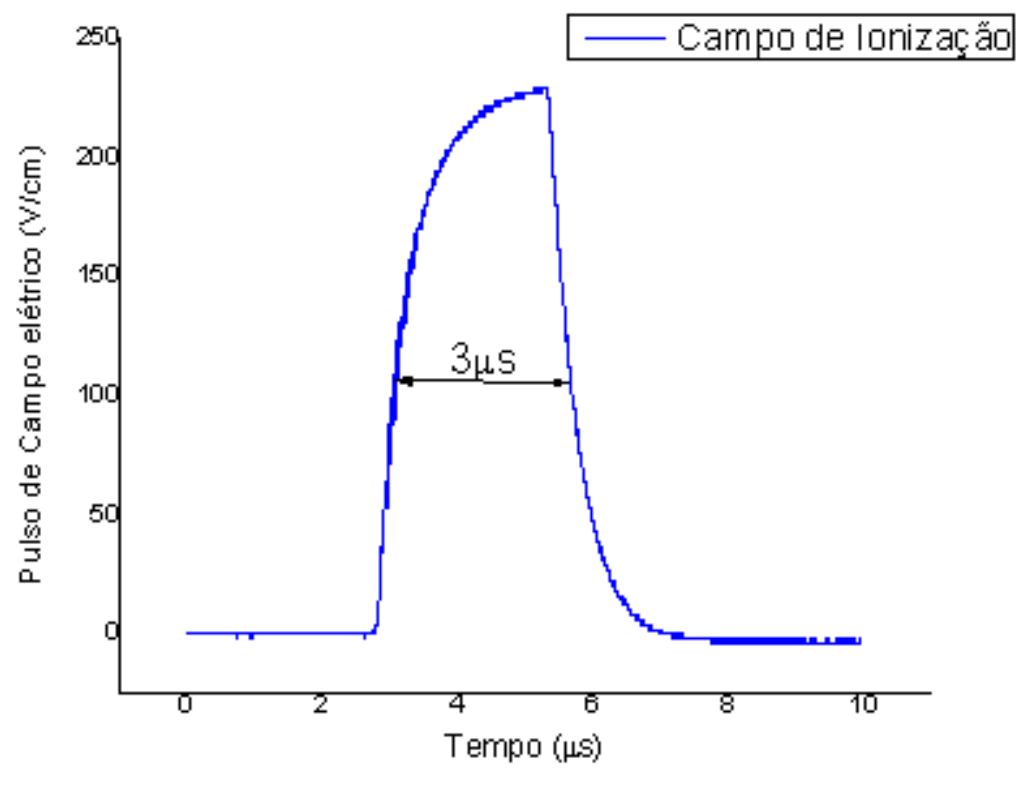

Figura 3.3 - Pulso de ionização aplicado na grade 1.

O campo necessário para ionização depende do número quântico principal $n$, na literatura (13) encontramos $E=\frac{1}{16} n^{4}$. A Figura 3.4 ilustra esse sistema de grades para ionização. Após a ionização o elétron é acelerado devido à diferença de potencial entre as grades até ser coletado num detector de elétrons CEM (Channelelectronmultiplier), sendo o sinal capturado no osciloscópio. A escolha de coletar elétrons e não íons foi devido a sua pequena massa e pequeno tempo de vôo que resolvem melhor a seleção de estados. 


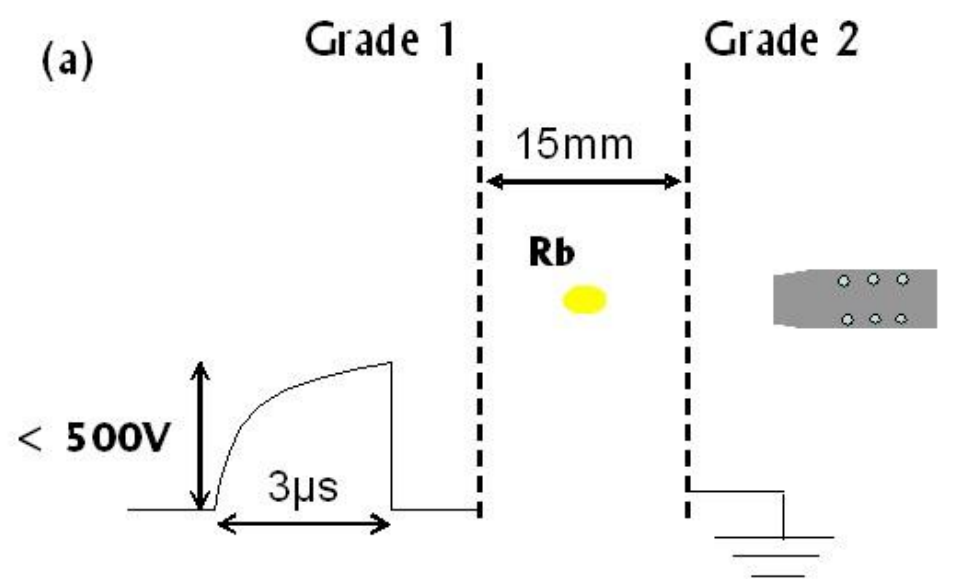

(a)

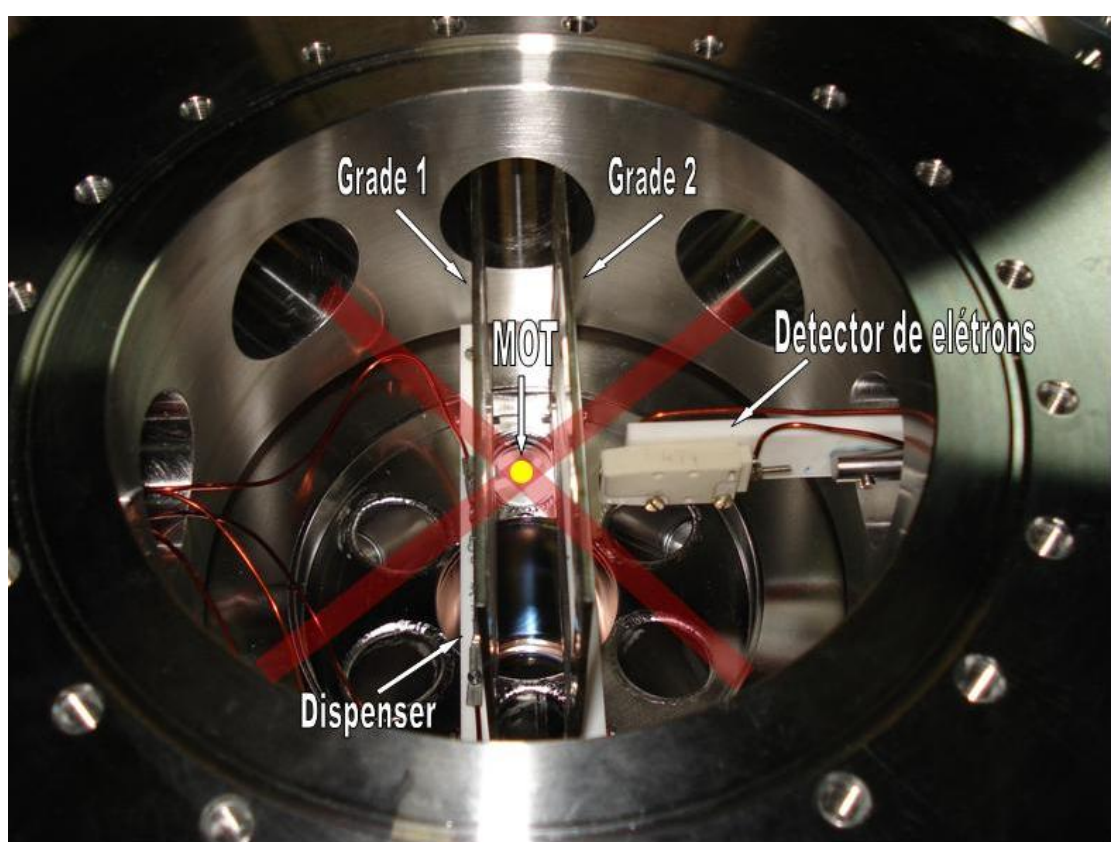

(b)

Figura 3.4 - (a) Esquema do pulso de HV aplicado na grade 1; (b) Foto do interior da câmara mostrando o sistema de detecção e o dispenser. 


\subsection{Sequência Experimental e Sistema de Aquisição}

A sequência temporal do experimento foi controlada por um gerador de pulso principal, o qual sincronizava o laser pulsado e a fonte de HV pulsada. Desta forma, podíamos definir um atraso temporal entre o pulso laser de excitação e o pulso de HV de detecção. Em geral, este atraso era definido entre $100 n s$ até $2 \mu s$. O sinal de elétrons resolvido no tempo era aquisicionado por um boxcar, o qual o integrava e realizava médias. Esta sequência pode ser observada na figura 3.5.

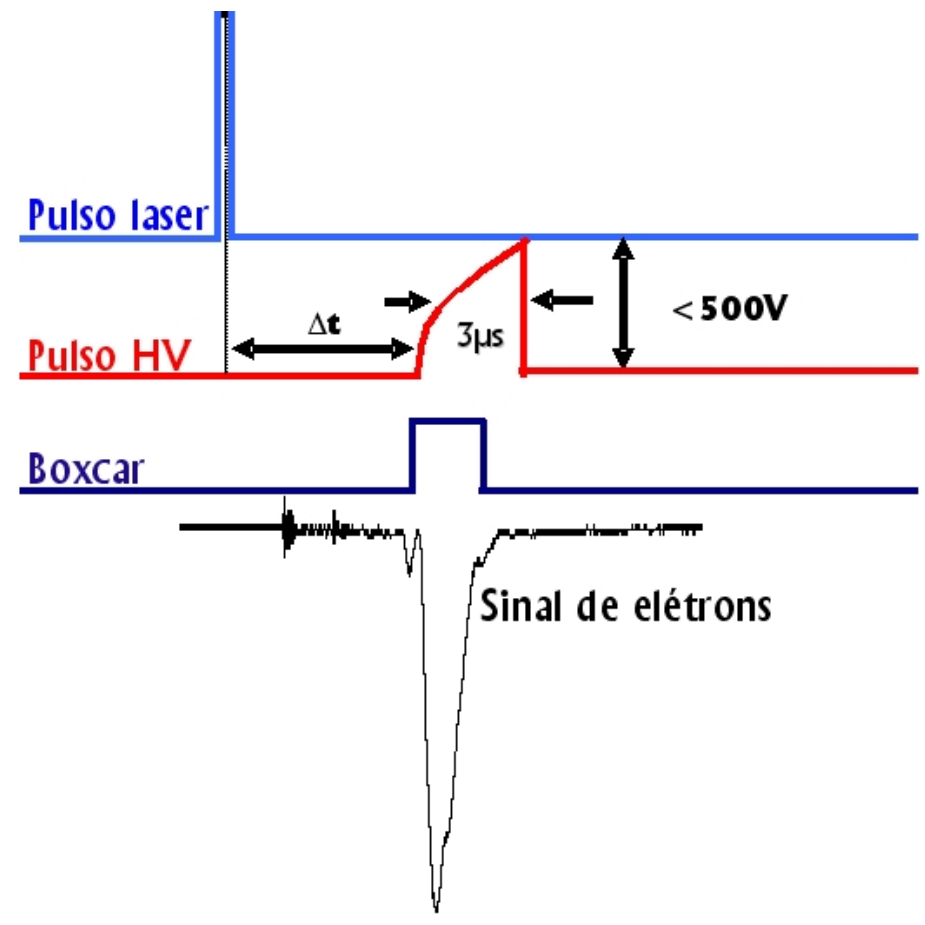

Figura 3.5 - Esquema da seqüência temporal do experimento para produção e detecção dos estados de Rydberg.

Paralelamente, a frequência do laser pulsado é controlada através de um programa de Labview, utilizando uma placa de aquisição da National, modelo PCI 6229. Varrendo-se a 
frequiência do laser foi possível observar um espectro típico de excitação dos átomos de Rydberg como mostra a figura 3.6. Devemos ressaltar que por razões técnicas este espectro foi obtido em intervalos de $0.5 \mathrm{~nm}$.

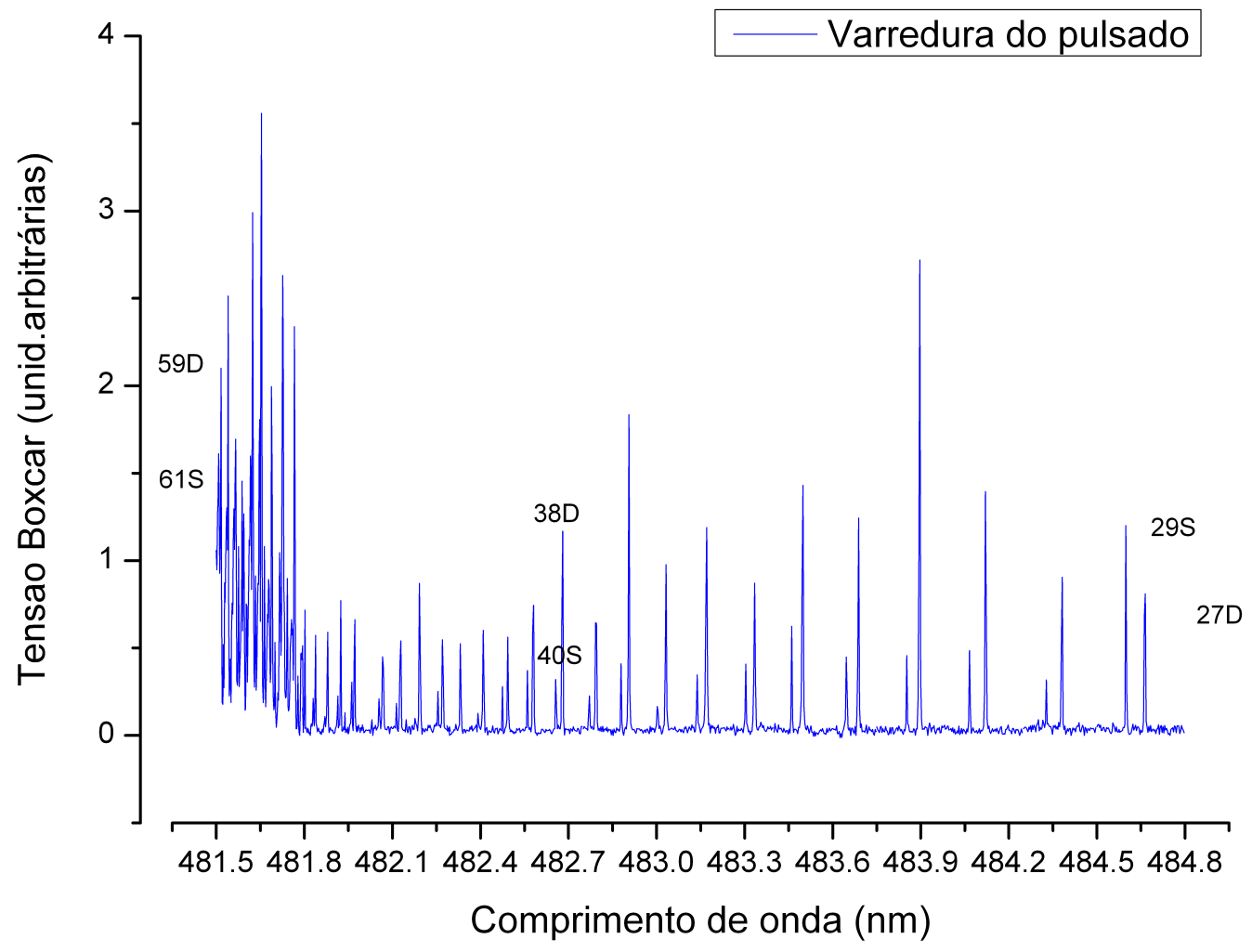

Figura 3.6 - Espectro típico obtido em nossas medidas.

O sinal de elétrons resolvido no tempo também era aquisicionado através de um osciloscópio digital, controlado via GPIB pelo computador. Na figura 3.7 mostramos um fluxograma do sistema de detecção de átomos de Rydberg e aquisição dos dados. 


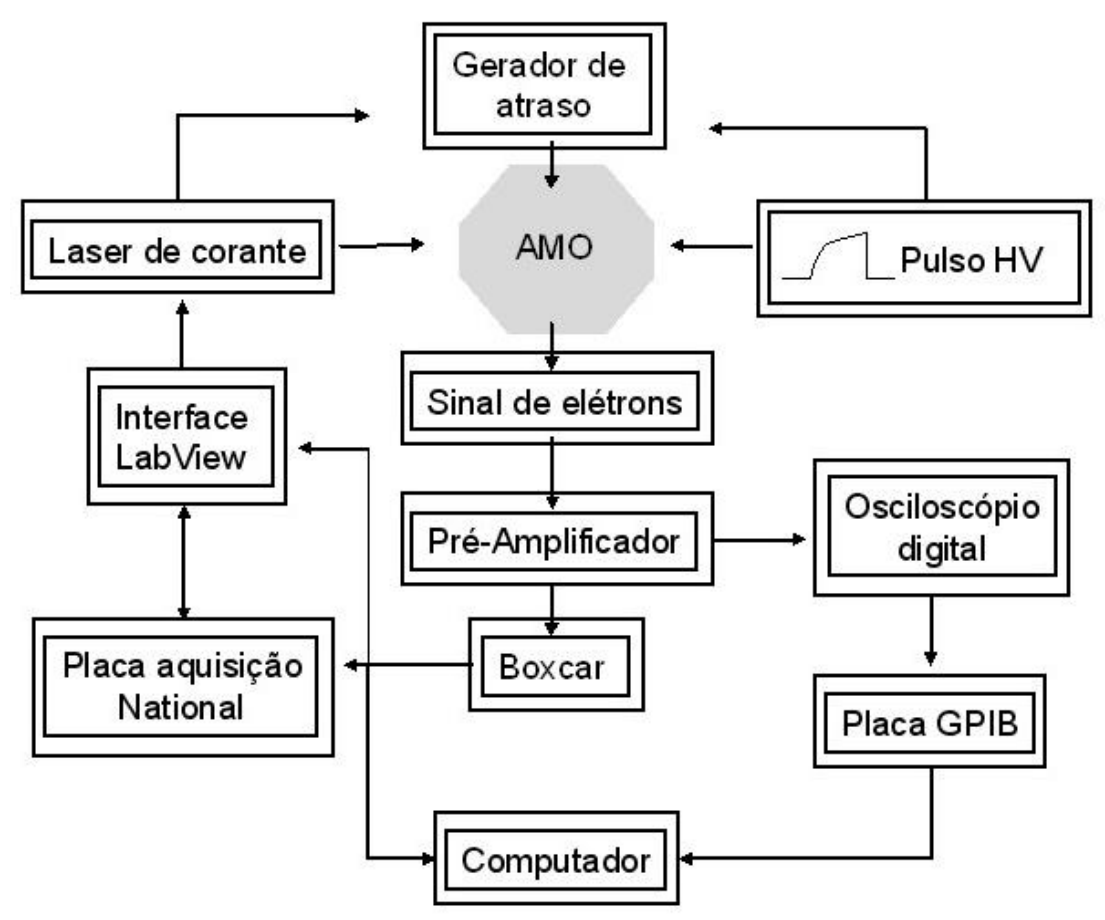

Figura 3.7 - Fluxograma representando o sistema de detecção e de aquisição de dados.

\subsection{Calibração do Campo Elétrico Residual}

$\mathrm{Na}$ armadilha, parcela dos átomos frios estão no estado $5 P_{3 / 2}$, e com o laser pulsado é possível transferí-los para estados $n P$. Esta é uma transição proibida por dipolo, mas que pode ser quebrada se houver um campo elétrico presente. Como observamos tal transição em nossa montagem, significa que há um campo elétrico residual. Nos experimentos é fundamental conhecermos este campo residual para o cancelarmos. O conhecimento preciso do campo DC na amostra é fundamental no tratamento de nossos resultados uma vez que buscamos entender como o efeito Stark DC age nos estados de Rydberg e modifica suas curvas de potencial.

Para calibramos este campo iniciamos excitando o estado $42 P$ identificado previamente no 
espectro de varredura. Em seguida, aplicamos uma diferença de potencial na grade 2, figura 3.4, e medimos a população em $42 P$ em função desta tensão. É sabido (43) que a população no estado P devido a este tipo de transição deve depender quadraticamente com o campo elétrico. Isto pode ser constatado na curva experimental da figura 3.8. Este procedimento nos permite determinar que havia uma campo residual da ordem de $1.5 \mathrm{~V} / \mathrm{cm}$ sobre a amostra atômica.

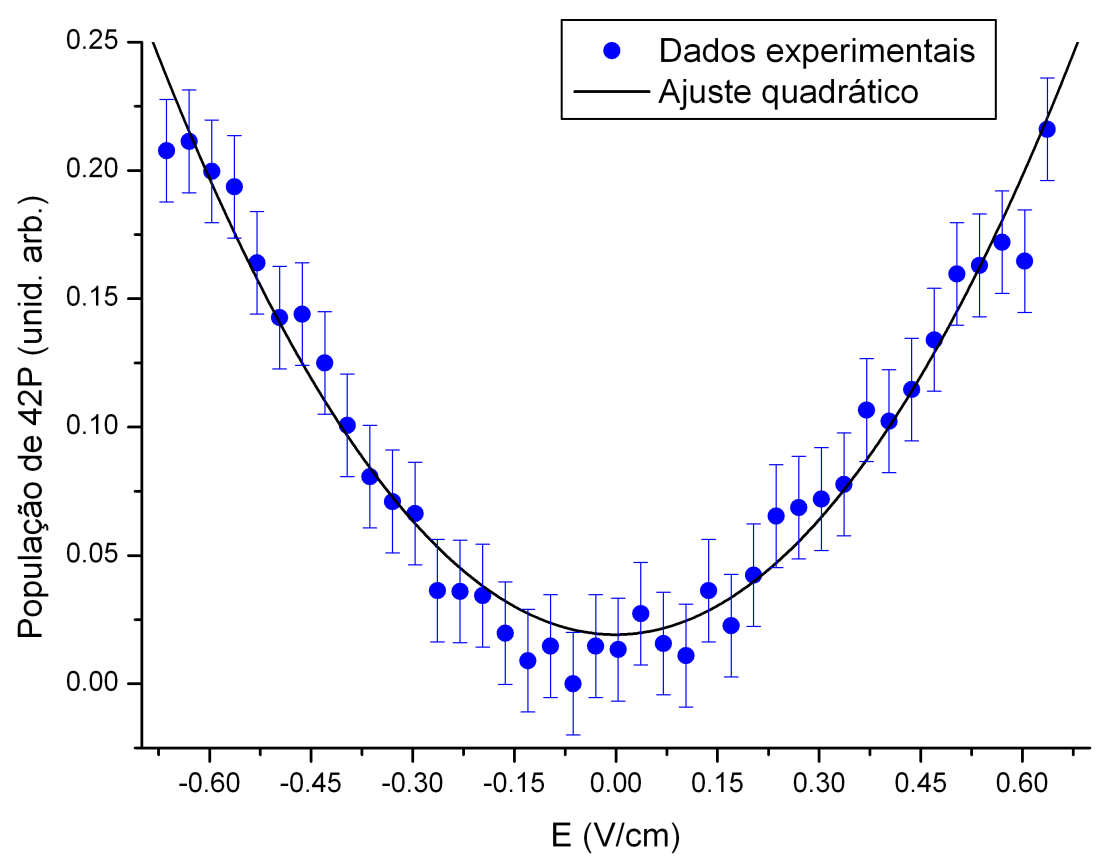

Figura 3.8 - População de 42P em função do campo total presenciado pelos átomos da armadilha. O campo elétrico residual é da ordem de $1.5 \mathrm{~V} / \mathrm{cm}$. 


\section{$4 \quad$ Resultados e Discussões}

Neste capítulo apresentamos os resultados envolvendo a excitação de pares atômicos $n D+$ $n D$ em uma armadilha magneto-óptica na presença de campo elétrico estático. Observamos a existência de população nos estados $(n+2) P$ e $(n-2) F$ quando excitávamos por laser estados $n D$ num intervalo de $28 \leq n \leq 41$. Tal efeito dependia fortemente da densidade atômica no estado $n D$, bem como do campo elétrico estático na amostra.

Trabalhos anteriores já observaram esse efeito $(2,14,15,44)$, contudo este foi associado ao movimento dos átomos em um potencial atrativo, com a conversão de energia potencial em cinética. Estes experimentos tinham duas grandes limitações: i) o campo elétrico estático na amostra foi apenas estimado; ii) a montagem experimental antiga de nosso grupo não permitia operarmos com curto intervalo de tempo entre excitação e detecção.

Nossa nova montagem não só permite um maior controle do campo elétrico estático na amostra, como também operar com curtíssimos tempos entre excitação e detecção. Assim, podemos esclarecer qual o papel do movimento e do campo elétrico estático no mecanismo de transferência de população do estado $n D$ para o estado $(n+2) P$. 


\subsection{Observação da Transferência de População}

Após a excitação com laser dos estados $n D$, observávamos população nos estados $(n+2) P$ e $(n-2) F$. Na figura 4.1 mostramos um típico sinal de elétrons obtido no experimento para excitação do estado $37 D$. Neste caso o tempo entre excitação e detecção era de $2,1 \mu s$. O campo elétrico DC era de $2 \mathrm{~V} / \mathrm{cm}$ com precisão de $80 \mathrm{mV} / \mathrm{cm}$.

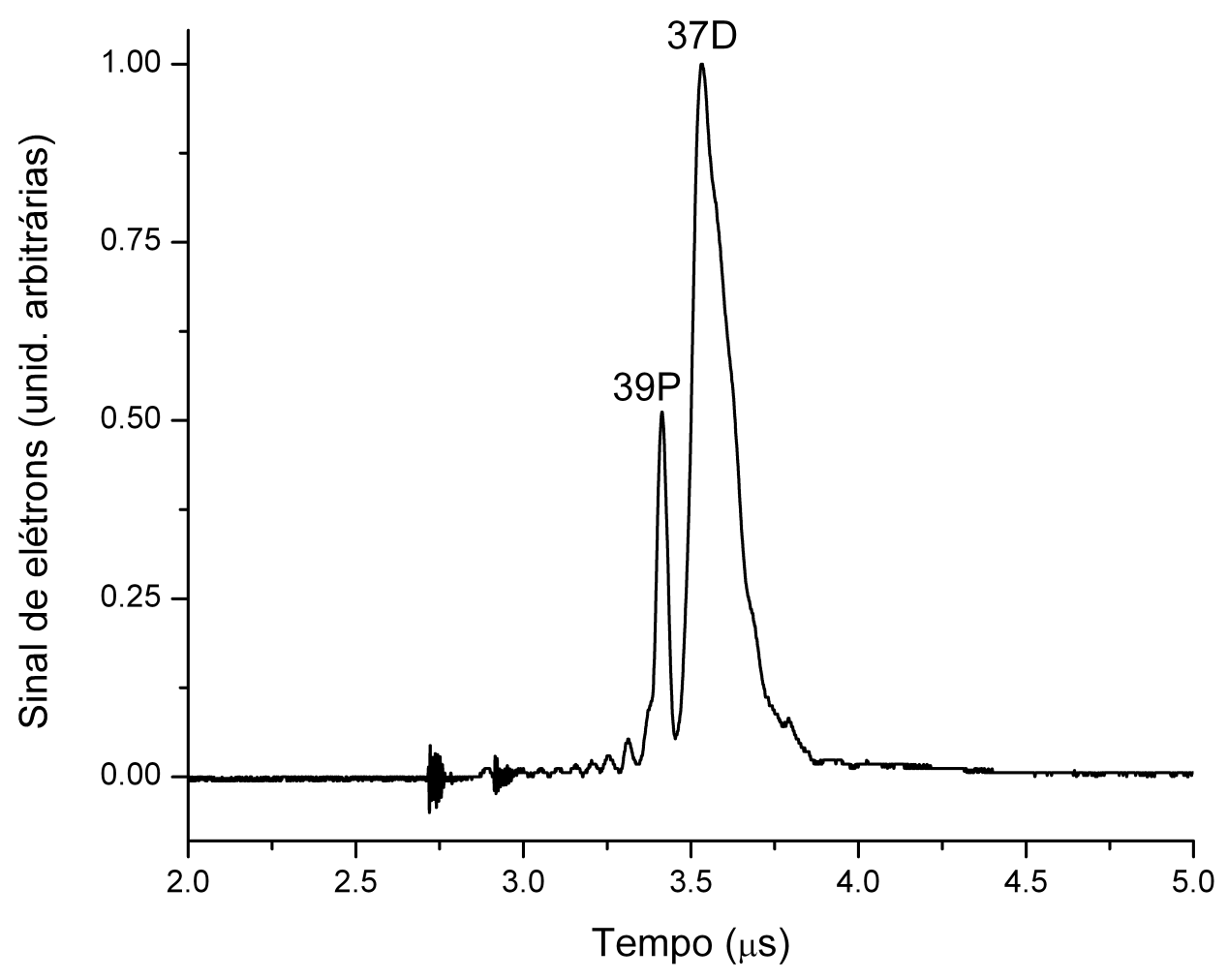

Figura 4.1 - Típico sinal de elétrons obtido na excitação de um estado nD.

O pico maior no centro corresponde à população no estado $37 D$ que foi excitado pelo laser pulsado. À esquerda temos um pico menor que foi verificado corresponder ao estado $39 P$. O estado $35 F$ não está visível devido a derivada do campo de ionização. À direita do pico de $37 D$ 
seu valor é muito pequeno o que prejudica a resolução de $35 F$. Devemos ressaltar que nem o estado $39 P$ nem o $35 F$ podem ser diretamente excitados pelo laser. Também observamos que nestas condições aproximadamente $14 \%$ da população em $37 D$ era transferida para $39 P$.

Este tipo de transferência de população foi observada para $28 \leq n \leq 41$. Neste intervalo podemos, em princípio, ter o seguinte processo: os átomos são excitados para o estado $n D$, e devido à um potencial atrativo começam a se mover um em direção ao outro. Em uma determinada distância internuclear este potencial cruza com outro que se correlaciona em grande distância aos estados $(n+2) P+(n-2) F$. Desta forma, a população seria transferida para estes estados com alguma energia cinética. Como no intervalo estudado ( $28 \leq n \leq 41)$ os estados $n D+n D$ tem mais energia potencial do que os $(n+2) P+(n-2) F$, a transferência devido ao movimento nos parece bem plausível. Assim, o processo seria descrito por:

$$
n D+n D \rightarrow(n+2) P+(n-2) F
$$

Fica claro da Eq. (4.1) que este se trata de um processo de dois corpos. Assim, o primeiro experimento realizado foi a dependência da população em $(n+2) P$ em função da densidade de população em $n D\left(\rho_{n D}\right)$ excitada pelo laser pulsado. O controle da densidade populacional inicial no estado $n D$ foi feito através da potência de rebombeio do laser de aprisionamento. Variando a potência de RF aplicada no modulador eletro-óptico controlávamos a potência do rebombeio, e assim a densidade no estado $5 P_{3 / 2}$ e consequentemente no estado de Rydberg $n D$. A variação da densidade foi aproximadamente de duas ordens de grandeza. O tempo entre o pulso laser e o pulso de ionização foi ajustado em aproximadamente $2,1 \mu s$. Dois integradores boxcar foram utilizados para acompanhar as populações dos estados $n D$ e $(n+2) P$.

Nas figura 4.2 (a) e (b) mostramos a população em $(n+2) P$ em função da densidade atômica 
em $n D\left(\rho_{n D}\right)$ para os estados $29 D, 33 D, 37 D$ e $41 D$ em duas condições de campo elétrico estático $(0 \mathrm{~V} / \mathrm{cm}$ e $1 \mathrm{~V} / \mathrm{cm})$. Ambos os eixos foram normalizados pelo seu maior valor, pois estamos interessados apenas no comportamento da curva. Os dados foram ajustados considerando que a população em $(n+2) P$ é proporcional a $\rho_{n D}^{s}$, onde $s=1,8 \pm 0,1$.

Observando o comportamento quadrático da população de $(n+2) P$ em função da densidade de população em $n D$ na ausência e presença de campo elétrico estático, nos leva a crer que o processo de transferência populacional $n D+n D \rightarrow(n+2) P+(n-2) F$ é regido por processos de dois corpo, em particular colisões. 


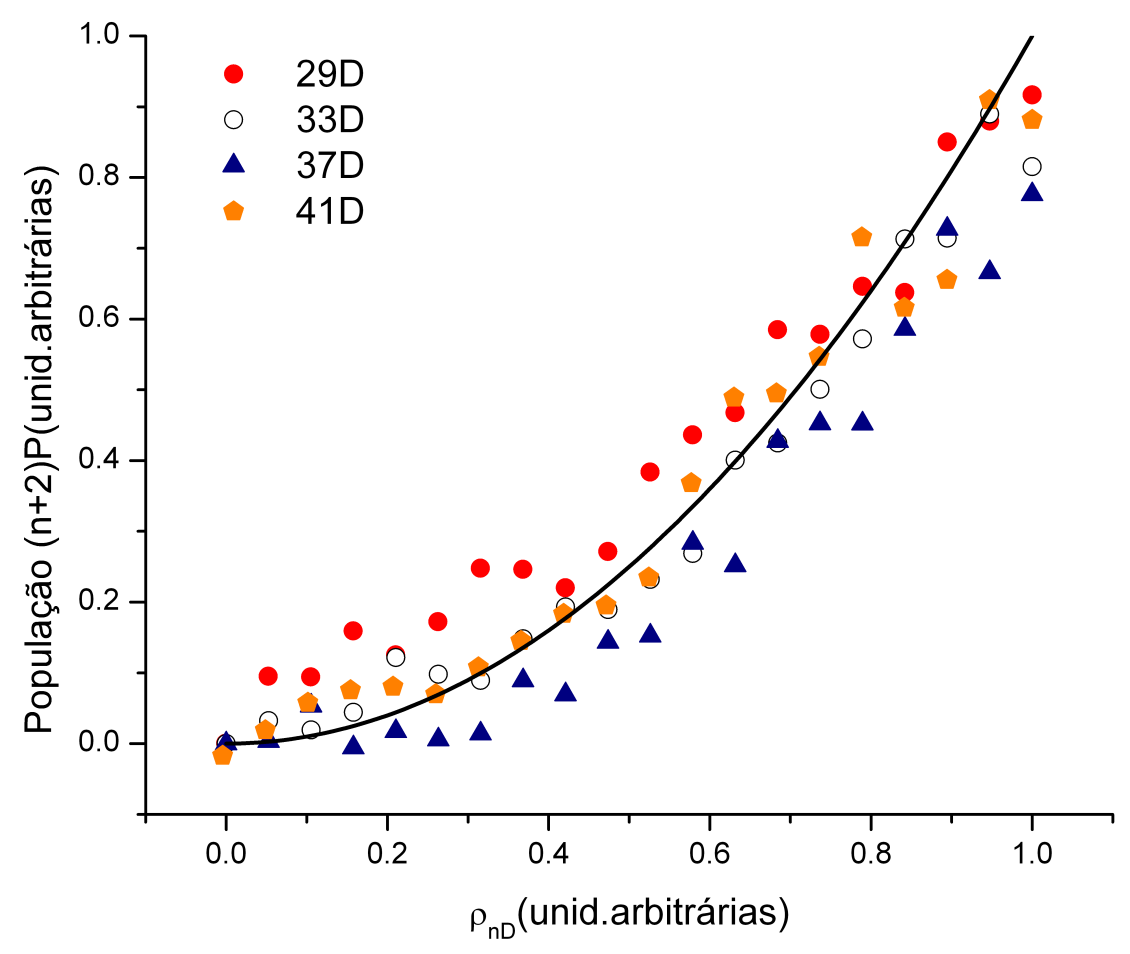

(a)

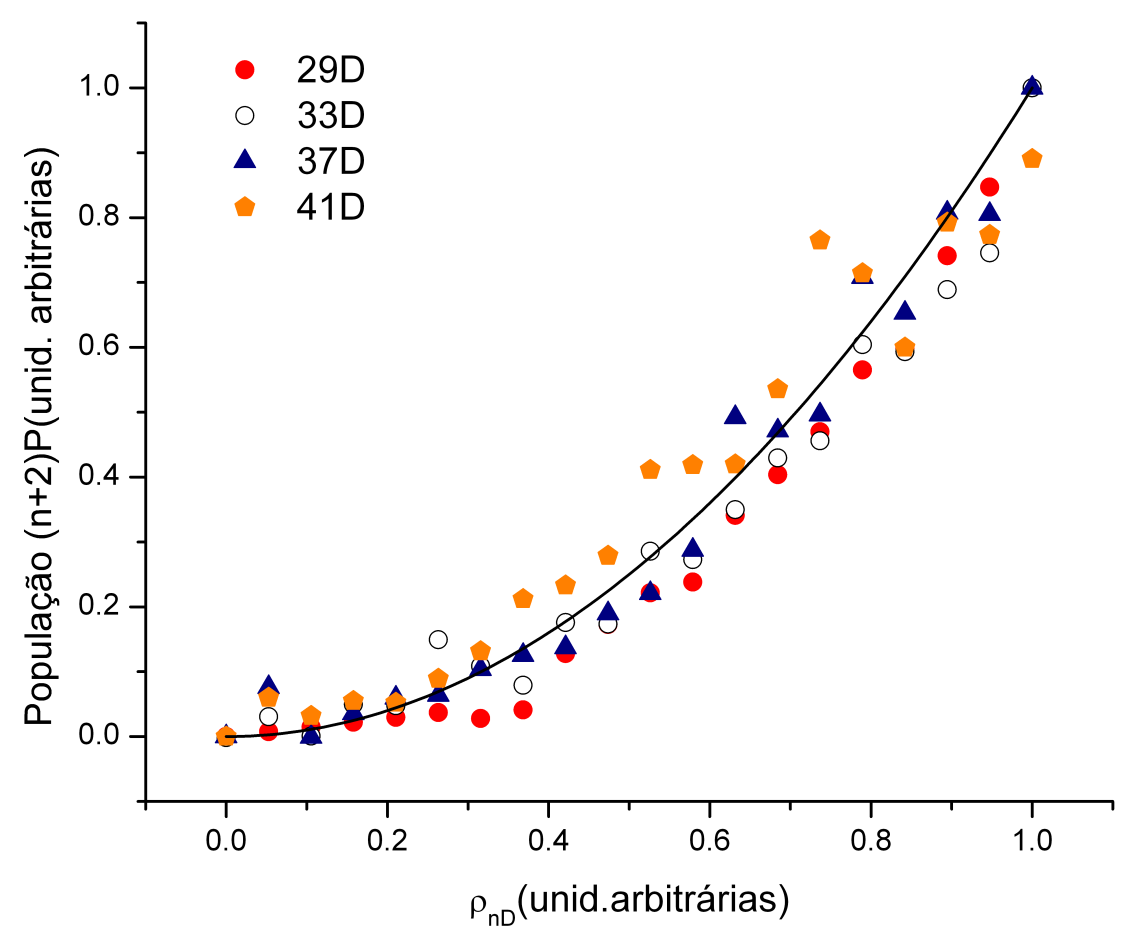

(b)

Figura 4.2 - População em (n+2)P em função de $n D$ para (a) $E=0 \mathrm{~V} / \mathrm{cm}$ e (b) $E=1 \mathrm{~V} / \mathrm{cm}$. A linha é um ajuste utilizando $\rho_{n D}^{s}$, onde $s=1,8 \pm 0,1$. 


\subsection{Caracterização do Processo de Transferência em Função do Número Quântico Principal e do Campo Elétrico Es- -tático}

Trabalhos anteriores de nosso grupo $(2,14,15,44)$ mostravam que a população em $(n+2) P$ em processo colisional de dois corpos envolvendo átomos de Rydberg pode ser escrita por:

$$
N_{(n+2) P}=K \rho_{n D}^{2}
$$

onde $K$ é uma constante de proporcionalidade que em princípio deve depender do número quântico principal, ou seja, $K(n)$.

A figura 4.3 mostra a constante $K$ em função do número quântico principal $(n)$, num intervalo de $28 \leq n \leq 41$, para diferentes valores de campo elétrico estático. Neste caso o intervalo de tempo entre excitação e detecção era de $2,1 \mu s$. Os valores foram normalizados para a unidade para facilitar a visualização.

Os resultados da figura 4.3 mostram um comportamento interessante na região entre $n=33$ e $n=39$. Observamos que na presença de campos entre 0 e $700 \mathrm{mV} / \mathrm{cm}$ a constante $K$ apresenta um mínimo em torno de $n=36$. A partir de um campo de $1 \mathrm{~V} / \mathrm{cm}$ esse comportamento desaparece, e a constante $K$ adquire um caráter monótono crescente. Este é um resultado interessante que nunca foi observado antes. Portanto, decidimos estudá-lo em mais detalhes em função do campo elétrico estático. Para isso excitamos o estado $37 D$ e varremos o campo elétrico, obtendo o gráfico da figura 4.4 .

No gráfico da figura 4.4 há dois efeitos responsáveis pela transferência de população para 


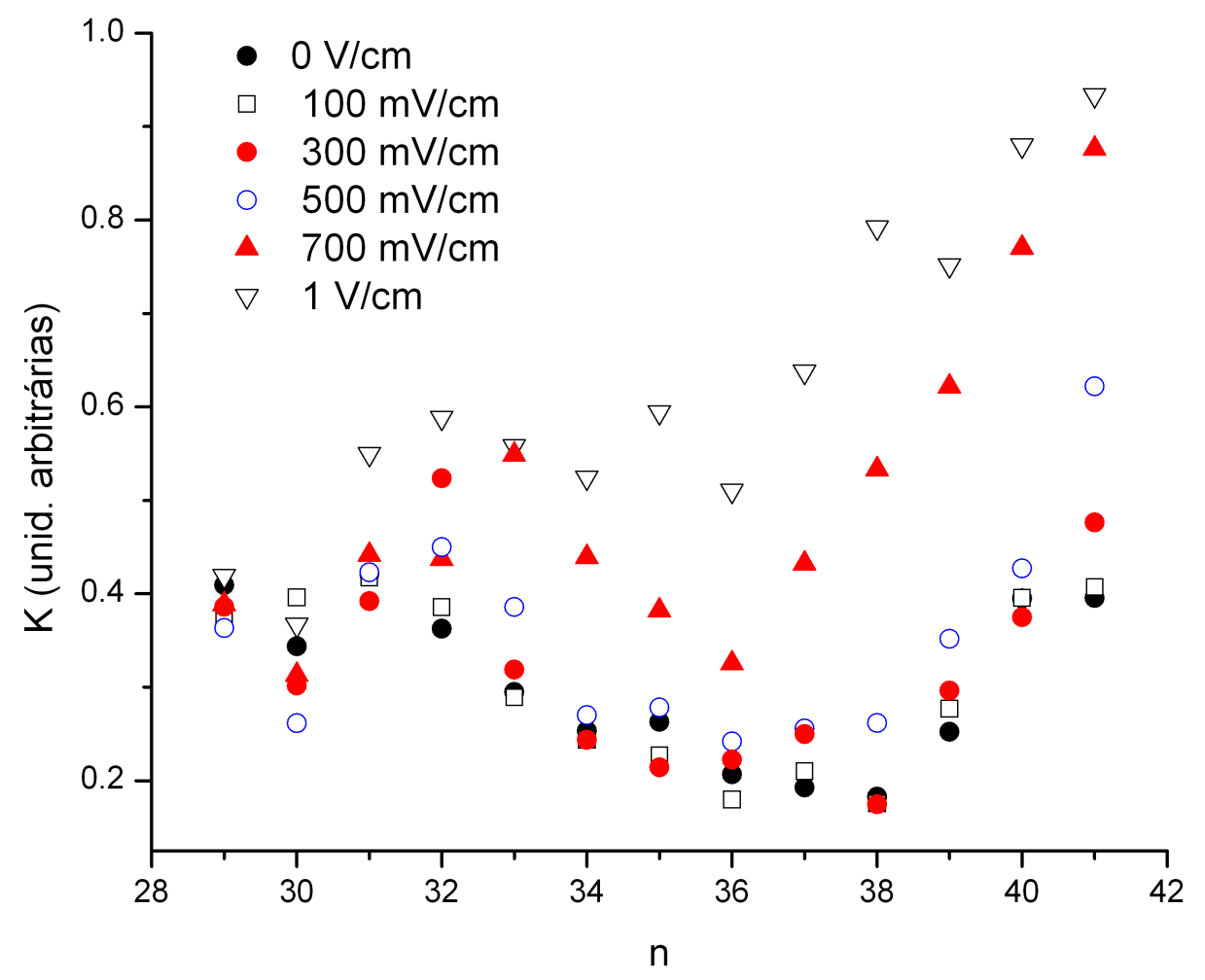

Figura 4.3 - Comportamento de K em função de n para diferentes campos elétricos estáticos. $O$ intervalo de tempo entre excitação e detecção era de $\Delta t=2,1 \mu \mathrm{s}$. 


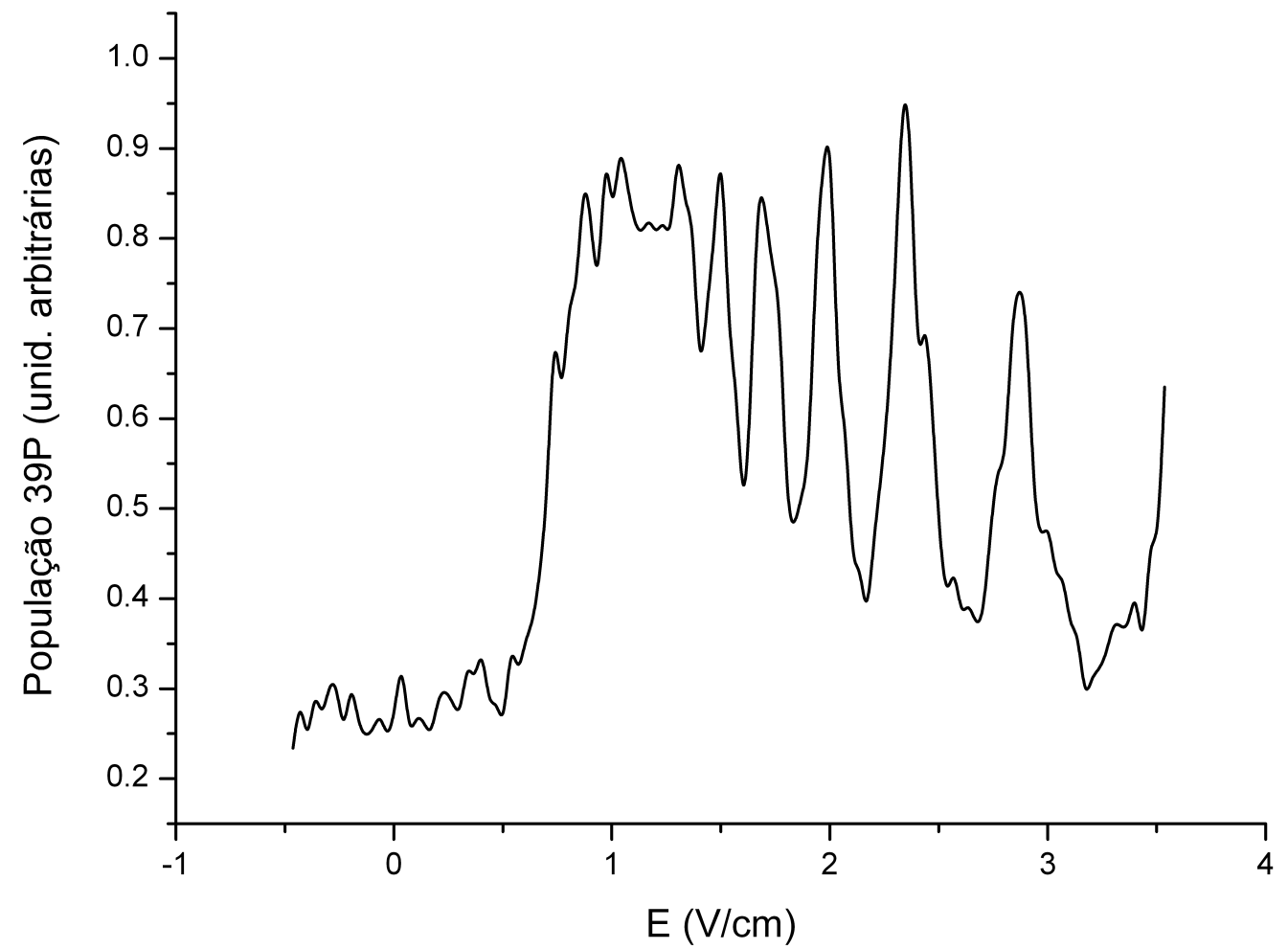

Figura 4.4 - População em 39P em função do campo elétrico estático quando o estado 37D era excitado. 
o estado 39P. Primeiramente, para campos maiores que $1 \mathrm{~V} / \mathrm{cm}$, ocorrem as chamadas colisões ressonantes (13). Neste caso através do campo elétrico podemos sintonizar a energia dos estados $37 D, 39 P$ e $35 F$ de forma que dois átomos no estado $37 D$ tenha a mesma energia que um no estado $39 P$ e outro no $35 F$ mesmo quando separados infinitamente. Devido a estrutura fina dos estados $D$ e $P$, esta condição pode acontecer em vários valores de campo, e por isso temos várias destas ressonâncias para um campo $>1 \mathrm{~V} / \mathrm{cm}$. Esse argumento é comprovado figura 4.5 que mostra o cálculo do mapa Stark próximo de $37 D+37 D$. Observe que os picos experimentais correspondem a cruzamentos do estado $37 D+37 D$ com estados de $39 P$.

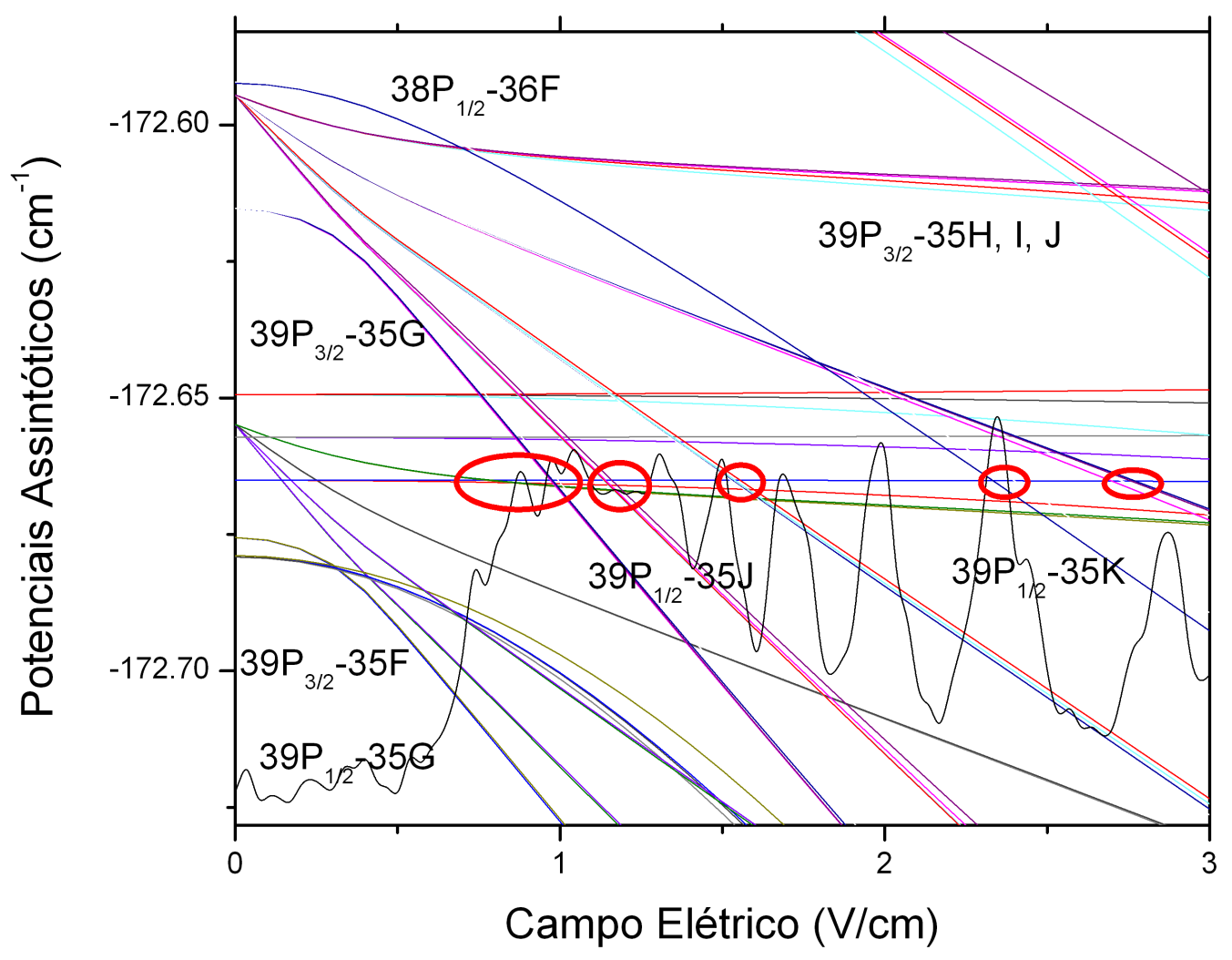

37D-37D

Figura 4.5 - Mapa Stark calculado pelo Prof. Shaffer da Universidade de Oklahoma. As regiões indicadas apresentam colisões ressonantes.

O segundo efeito, para valores de campo $<1 \mathrm{~V} / \mathrm{cm}$, se deve a ressonâncias moleculares semelhantes ao observado por Overstreet e colaboradores (30). Ou seja, os potenciais moleculares 
correlacionados ao estado $n D+n D$ apresentam cruzamentos com os potenciais associados aos estados $(n+2) P+(n-2) F$ em curtas distâncias internucleares. Isto acaba levando a transferência de população para o estado $(n+2) P$. Este modelo está em concordância com as interpretações utilizadas em outros experimentos em nosso laboratório $(2,15,44)$. Contudo, nos falta demonstrar que o movimento atômico tem um papel importante nesta interpretação envolvendo estados atrativos.

\subsection{Evolução Temporal da Transferência de População}

Com o intuito de desvendar a importância do movimento na transferência de população do estado $n D$ para $(n+2) P$, medimos a evolução temporal da população em $39 P$ para vários valores de campo elétrico estático. Na figura 4.6, mostramos os resultados da população em 39P normalizada em função do tempo entre excitação e detecção, para vários valores de campo. Os valores da população foram normalizados porque estamos interessados apenas no comportamento temporal. Devemos ressaltar também que o valor máximo da população era obtido em torno de $3 \mu s$.

No gráfico da figura 4.6 o primeiro fato surpreendente é que existe uma fração expressiva de população no estado $39 P$, entre 30 - 60\% do valor máximo, mesmo para tempos muito curtos, como por exemplo 100ns. Nesta escala de tempo os átomos não se moveram o suficiente para sustentar a idéia de que a população em $39 P$ é devido à transferência colisional em um potencial atrativo. Nesta escala de tempo também podemos descartar ionização Penning e radiação de 


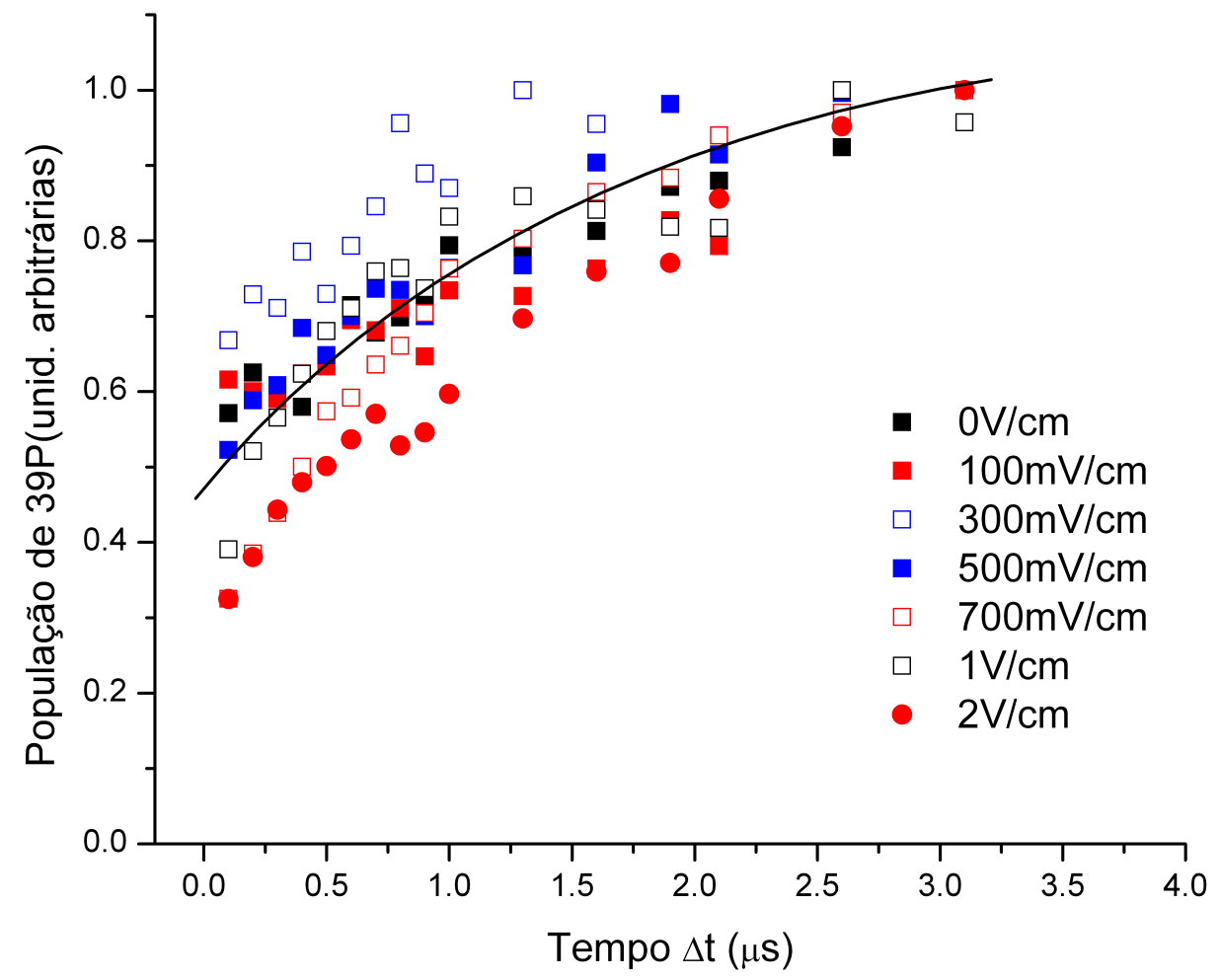

Figura 4.6 - População em $39 P$ em função do tempo entre excitação e detecção. 
corpo negro (22) como responsáveis por este efeito. Também podemos descartar efeitos de ionização por campo na detecção $(18,19)$.

Outro fato surpreendente é que a evolução temporal não parece depender do campo elétrico aplicado na amostra. Isto é meio contraditório com o modelo onde os pares atômicos iniciam sua colisão em um potencial atrativo correlacionado ao estado $n D+n D$, e após o movimento e a mudança de potencial terminam em um estado $(n+2) P+(n-2) F(15)$. Afinal, se este modelo estivesse correto, conforme o campo elétrico é aumentado o estado $(n+2) P+(n-2) F$ iria se aproximar do estado $n D+n D$, e a interação entre os estados levaria a alteração dos pontos de cruzamento e dos próprios potenciais. Assim, a evolução temporal da transferência de população deveria depender do campo elétrico aplicado.

O modelo baseado no movimento (15) prevê que a constante $K(n)$ deve depender do tempo, pois pares atômicos localizados em distâncias internucleares distintas contribuirão para a popu-lação em $(n+2) P$ em tempos distintos. Assim, para elucidar o efeito do movimento nestas transferências de população, medimos $K(n)$ em função de $n$ para vários campos elétricos com $100 n s$ entre excitação e detecção. Os resultados estão mostrados na figura 4.7.

Do gráfico da figura 4.7 fica claro que a dependência de $K$ com o número quântico principal não é influenciada pelo intervalo de tempo entre a excitação e a detecção. Apenas o valor absoluto de $K$ depende deste intervalo de tempo como mostrado na figura 4.6. Isto a princípio sugere que movimento não é responsável pela transferência de população, pelo menos no intervalo entre 0 e $3 \mu s$ entre excitação e detecção.

Então fica a pergunta como podemos explicar nossos resultados e os comportamentos observados? Para responder esta pergunta nos associamos ao grupo do Prof. J. Shaffer da Universidade de Oklahoma. Este grupo é especialista no cálculo de potenciais e ressonâncias mo- 


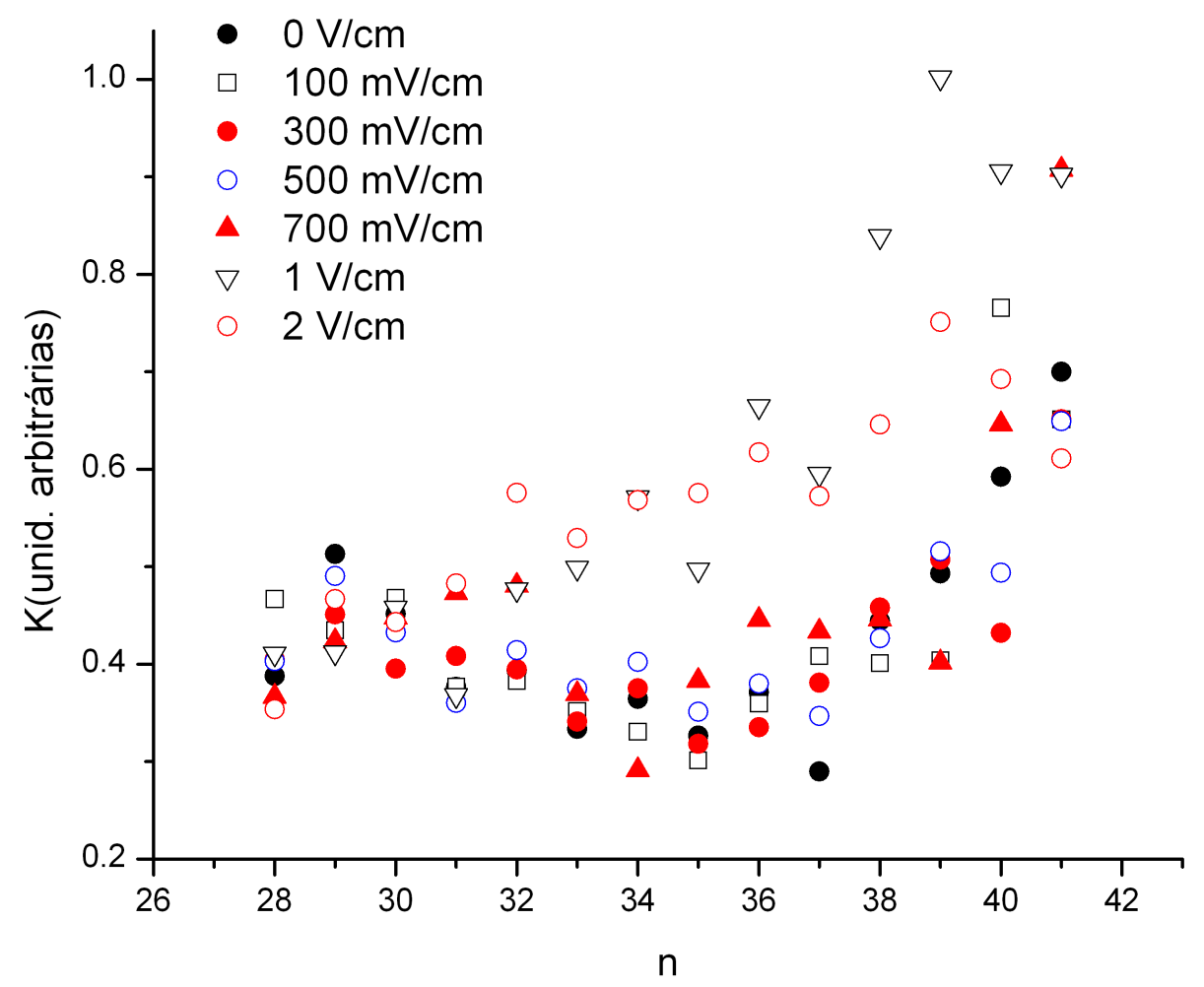

Figura 4.7 - Comportamento de K em função de n para diferentes campos elétricos estáticos. $O$ intervalo de tempo entre excitação e detecção era de $\Delta t=100 \mathrm{~ns}$. 
leculares entre átomos de Rydberg na presença de campos elétricos. Recentemente, este grupo modelou resultados nossos envolvendo estados $n S+n S$, os quais foram interpretados como ressonâncias moleculares devido efeitos Stark AC e DC e interações multi-polares (45).

O cálculo destes potenciais considerando várias interações multipolares, estrutura fina e efeito Stark AC e DC não é uma tarefa fácil, e na realidade poucos lugares no mundo dispõem de capacidade computacional para tanto. Devido ao fato do Centro de Estudos de Tornados se localizar em Oklahoma, é que o grupo do Prof. Shaffer tem acesso a um dos mais rápidos supercomputadores do mundo. Mesmo assim são necessárias várias semanas de uso de máquina para cálculo de tais potenciais, pois envolve a diagonalização de matrizes muito grandes.

Tais cálculos permitiram o entendimento do processo de população no estado $n P$. Isto ocorre devido ao fato que próximo ao potencial $n S+n S$ existe uma ressonância molecular do estado $n P+(n-1) P$. Na realidade, conforme a distância internuclear $(\mathrm{R})$ diminui, o potencial $n P+(n-1) P$ passa a ganhar um caráter $n S+n S$, o qual é caracterizado pelo fator $C(R)=$ $\langle n S+n S \mid n P+(n-1) P\rangle$, onde os estados envolvidos já não são mais os estados atômicos puros, mas sim os calculados considerando várias interações multipolares, estrutura fina e efeito Stark AC e DC. Como exemplo, mostramos na figura 4.8 (a) os potenciais calculados em torno do potencial $32 S+32 S$ considerando todas estas interações. Na figura 4.8 (b), mostramos o fator $C(R)$ para este caso; podemos observar claramente que conforme $R$ diminui $C(R)$ aumenta.

Existem também outros estados próximos ao estado $32 S+32 S$, como por exemplo, o $32 D+30 P$. Mas os cálculos mostraram que estes não são importantes. O termo dominante na interação entre o potencial $32 S+32 S$ e o $32 P+31 P$ é a interação dipolar. Os cálculos também mostraram que para estes estados em particular não há dependência com o campo elétrico estático, condizente com as observações experimentais. 

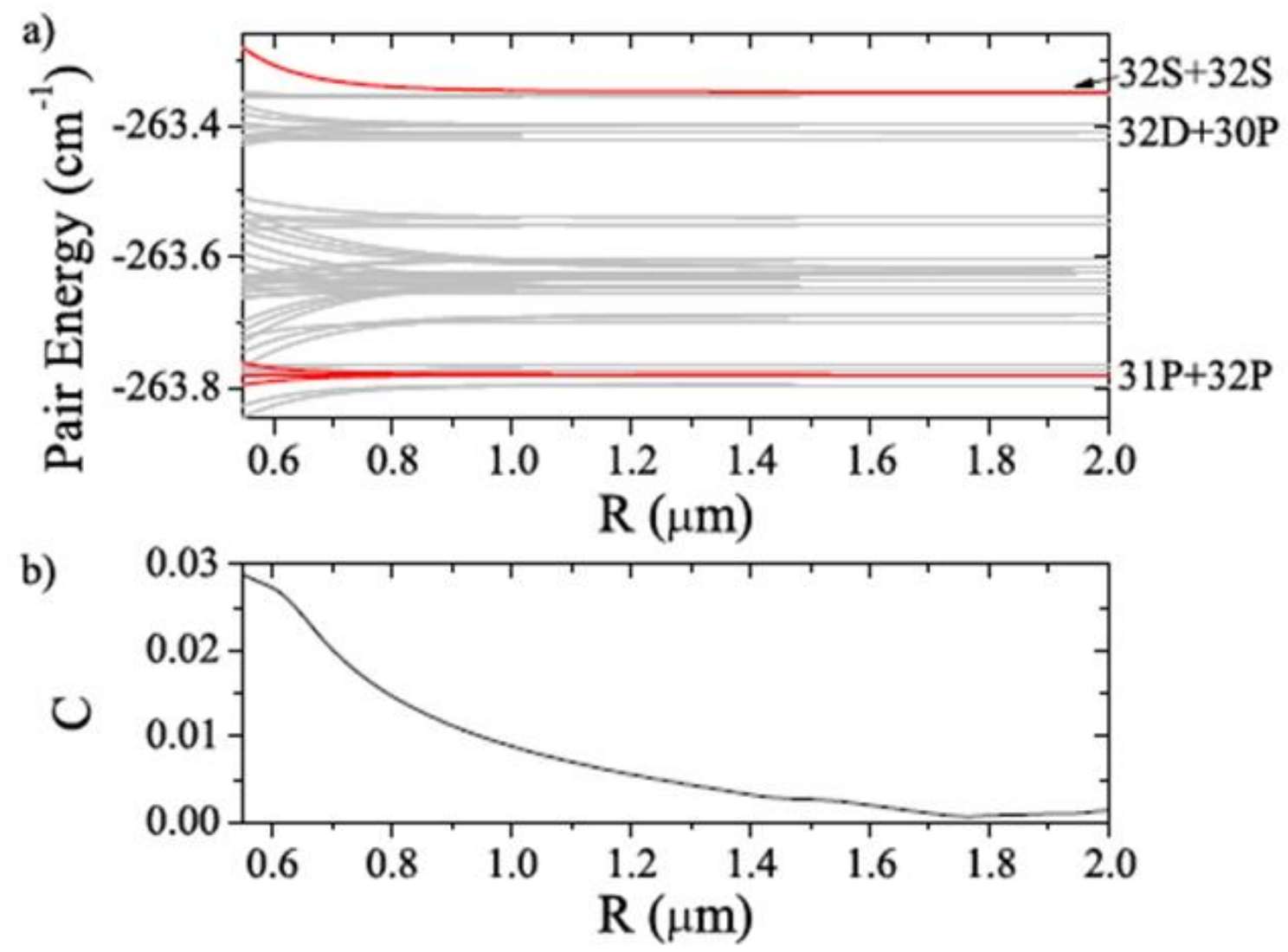

Figura $4.8-($ a) Potencial $32 S+32 S$ e estados próximos para $M=1$ e um campo elétrico $D C$ de $500 \mathrm{mV} / \mathrm{cm}$. O Potencial para $32 P+31 P$ é energicamente abaixo do $32 \mathrm{~S}+32 \mathrm{~S}$ para todos os $R$; (b) $C(R)=\langle n S+n S \mid n P+(n-1) P\rangle$. 
Uma vez resolvido os potenciais foi proposto um modelo que considera 3 níveis, o estado $5 P+5 P$ (como fundamental), o estado $32 S+5 P$ (intermediário) e o $32 P+31 P$ (final). As equações da matriz densidade foram resolvidas numericamente sem parâmetros ajustáveis considerando a excitação do laser pulsado. Devemos salientar que o laser estava sintonizado na transição $5 P \rightarrow 32 S$, de forma que a princípio estaria sintonizado para o azul do estado $32 P+31 P$. Porém, devido ao efeito Stark AC a transição $32 S+5 P \rightarrow 32 P+31 P$ fica ressonante e é possível a direta excitação do estado $32 P$.

Em outras palavras, quando o estado $32 S$ é excitado com um laser pulsado, há uma probabilidade não nula de excitarmos tal ressonância molecular e assim transferir população para o estado 32P. Como o fator $C(R)$ depende da distância internuclear, a fração de pares excitados também depende da distância internuclear. Assim, para se obter a fração total excitada é preciso realizar uma integral entre 0.6 e $2 \mu m$. Além disso, as equações da matriz densidade precisam ser resolvidas no tempo até 25ns. Após este tempo apenas decaimento espontâneo e radiação de corpo negro contribuirão.

Na figura 4.9 é mostrado o sinal de elétrons obtido, o qual evidencia a população em $32 P$. Devemos ressaltar que a fração de população observada no estado $n P$, em torno de $3 \%$, é consistente com os cálculos teóricos.

Baseados nesses resultados com os experimentos $n S+n S$, o grupo de Oklahoma propôs a existência de ressonâncias entre os potenciais $n D+n D$ e $(n+2) P+(n-2) F$. Estas ressonâncias que para $28 \leq n \leq 41$, que ocorrem entre 0.5 e $1.5 \mu m$, são populadas diretamente pelo pulso de laser, e podem ser detectadas imediatamente. Isso explica porque observamos população em $(n+2) P$ para tempos tão curtos quanto 100ns. Ou seja, o par atômico, no estado $5 P+$ $5 P$, localizado entre 0.5 e $1.5 \mu m$ absorve dois fótons ressonantes em $480 \mathrm{~nm}$ e é transferido imediatamente para a ressonância $(n+2) P+(n-2) F$. 


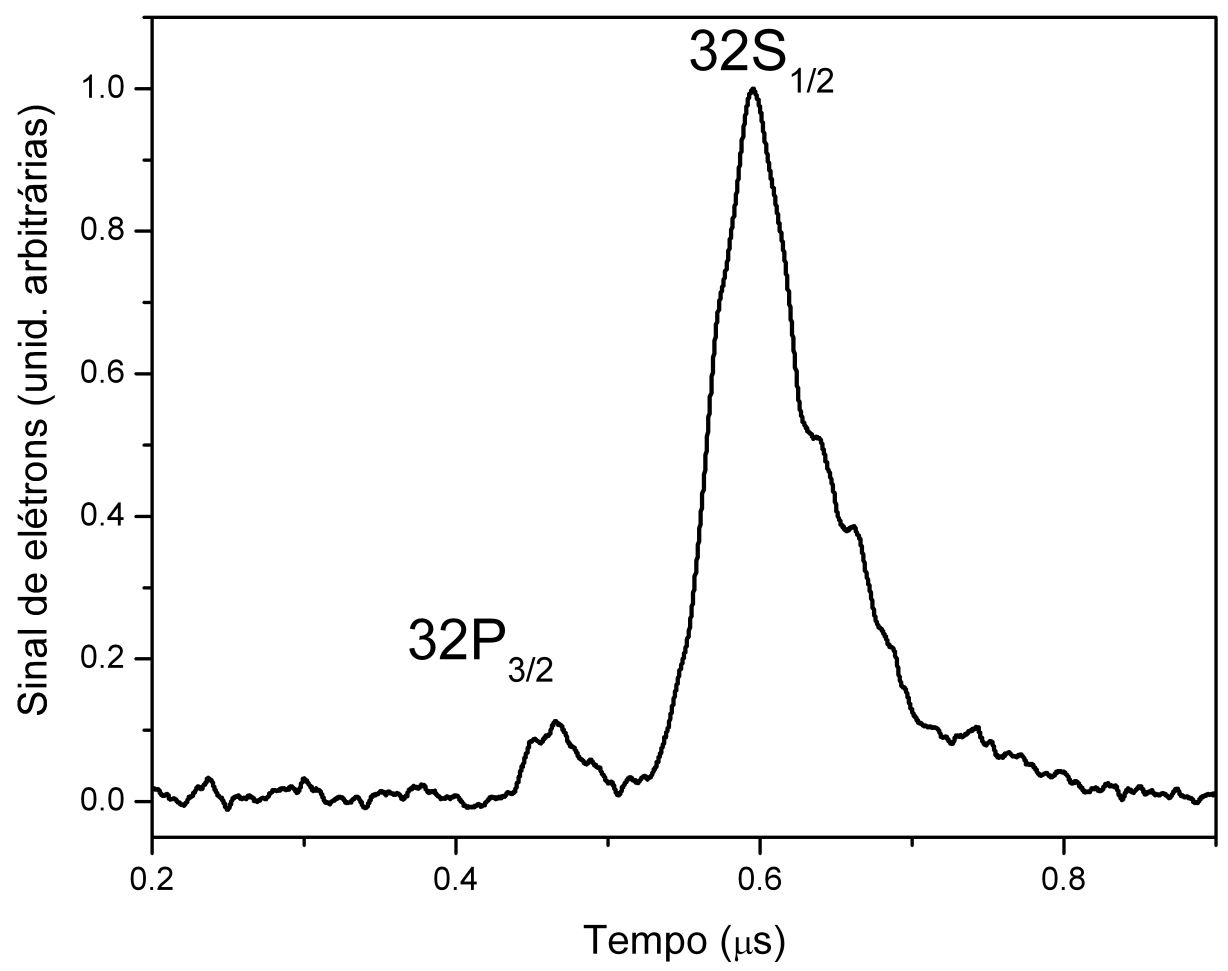

Figura 4.9 - Sinal de elétrons resolvido no tempo mostrando os estados $32 P$ e $32 S$. 
Isto também explica porque observamos um comportamento de dois corpos, ou seja uma dependência quadrática na densidade. Como a população do estado $(n+2) P$ depende quadraticamente da população no estado $5 P$, já que é um processo de dois corpos na ressonância molecular e a população no estado $n D$ é linearmente dependente da população no estado $5 P$, devido a excitação de um fótons, temos que a população no estado $(n+2) P$ é quadrática com a população em nD.

O comportamento de $K(n)$ em função de $n$ para vários campos é mais complicado de explicar, pois realmente requer uma simulação numérica que considere o efeito Stark AC e DC. Tal efeito é importante ser levado em consideração pois afeta diretamente a posição dos cruzamentos e seus formatos (30). No presente momento, tais simulações estão em andamento no grupo de Oklahoma.

Apesar do sucesso em explicar nossos resultados, o modelo de ressonância é incapaz de explicar a evolução temporal da população no estado $(n+2) P$. Existem duas possibilidades para explicar este comportamento. Uma, onde o movimento atômico ainda é importante e contribui para evolução temporal da população no estado $(n+2) P$, depois da excitação do laser. Neste caso, nosso modelo semi-clássico (15) envolvendo movimento em um potencial atrativo precisa ser reestruturado, ou quem sabe até descartado. Requerendo assim um modelo completamente quântico.

A outra possibilidade é que o movimento não é importante na escala de tempo de até $3 \mu s$, e que a evolução temporal é advinda da evolução temporal da função de onda eletrônica, antes da detecção pelo campo elétrico pulsado. Esta possibilidade teórica foi desenvolvida pelo grupo de Oklahoma. Segundo esta teoria, os elementos fora da diagonal envolvendo os potenciais $(n+2) P+(n-2) F$ não são nulos, fazendo então que haja uma evolução temporal da função de onda eletrônica do par atômico. Dependendo desta função de onda a detecção utilizando 
o campo elétrico pulsado poderia ser prejudicada, e nem todos os pares seriam detectados em tempos curtos. Em outras palavras, para tempos curtos a função eletrônica de uma parcela dos pares atômicos seria tão diferente da função de onda eletrônica de um estado $(n+2) P$, que o campo pulsado não seria capaz de ionizá-lo, e assim não haveria detecção. Conforme o tempo aumenta e os átomos se afastam, esta função de onda eletrônica do par evoluiria naturalmente para duas funções de onda atômicas independentes. Assim, a eficiência de detecção aumentaria e o sinal de elétrons também. Esta hipótese deve ser considerada porque a escala temporal observada no experimento é da mesma ordem de grandeza do previsto pela teoria. A Eq. 4.3 ilustra como seria esta função de onda.

$$
\Psi(t)=a(t) \Psi_{D D}(t)+b(t) \Psi_{P}(t)+c(t) \Psi_{F}(t)
$$

Um outro argumento, para sustentar esta afirmação, pode ser feito através de um cálculo simples. Consideremos átomos com temperatura de $300 \mu K$, que corresponde uma velocidade média em torno de $30 \mathrm{~cm} / \mathrm{s}$. Acreditamos que as ressonâncias ocorrerão para o $n D+n D$ em regiões similares ao $n S+n S$, visto que os números quânticos principais são próximos, ou seja, ocorrerão entre 0.6 e $1.6 \mu m$. Assim, para distâncias superiores a $1.6 \mu m$ podemos considerar o par atômico como dois átomos independentes. Basicamente os átomos terão que percorrer uma distância em torno de $1 \mu m$ antes de serem independentes. Com tal temperatura, isto equivale a um intervalo de tempo da ordem de $3 \mu s$, o que é consistente com nossas observações.

Contudo, novos experimentos serão necessários para testar estas hipóteses. 


\section{Conclusões}

Neste trabalho buscamos compreender os mecanismos que podem levar a mudança de estados atômicos de átomos de Rydberg frios através de interação de ultralongo alcance. Estudamos especificamente o processo colisional $n D+n D \rightarrow(n+2) P+(n-2) F$ na presença de campo elétrico estático em um novo e moderno aparato experimental. Como mencionamos ao longo desta dissertação, entender tal mecanismo na sua forma mais elementar representa um significativo avanço na área de física atômica e uma eventual aplicação em computação quântica.

Nosso grupo de pesquisa vem trabalhando com processos colisionais entre átomos de Rydbeg frios a cerca de dez anos. Os resultados obtidos ao longo desses anos $(2,14,15,44)$ apontavam para uma interpretação onde o movimento atômico não poderia ser descartado. Um modelo semi-clássico baseado no movimento do par atômico sob ação de um potencial atrativo foi elaborado por nosso grupo e concordava muito bem com os resultados até então obtidos (15).

Entretanto, ficou claro nos resultados apresentados neste trabalho que ressonâncias moleculares estão presentes no sistema estudado, pois observamos população no estado $(n+2) P$, numa escala de tempo muito curto entre excitação e detecção (100ns). Observamos uma transferência de população da ordem de $10 \%$ da população inicial nesta escala de tempo. A idéia de movimento nesta escala de tempo é completamente descartada. Tais ressonâncias moleculares se mostraram sensíveis ao campo elétrico estático presente na amostra, como observado na figura 
4.7.

Por outro lado, observamos uma evolução temporal crescente da população no estado $(n+$ 2) $P$, atingindo um máximo em torno de $3-4 \mu s$. A princípio, poderíamos imaginar que a radiação de corpo negro fosse a responsável por tal transferência de população como observado em trabalhos anteriores do grupo $(2,44)$. Uma vez que nesta região do espectro $(n=30-70)$ a energia térmica $k T$ à $300 K$ é da ordem da separação entre os níveis, e assim os fótons do campo de radiação podem induzir transições entre estados atômicos próximos (46).

Modelando a transferência devido à radiação de corpo negro como um sistema de equações de taxa, não é possível explicar o aumento de população no tempo. Outro resultado que fortalece tal afirmação é que o comportamento quadrático da população $(n+2) P$ em função da população em $n D$ apresentado na secção 4.1. Se fosse apenas transferência de população via radiação de corpo negro o comportamento seria linear, pois o sistema de equações de taxas só apresenta termos lineares nesta situação (47).

Um fato surpreendente observado foi que essa evolução temporal da população não depende do campo elétrico aplicado, o que prejudica a idéia de movimento do par atômico sob ação de um potencial atrativo (15). Uma vez que é de se esperar que variando o campo elétrico, a região de cruzamento, ou de colisão, varie e o próprio potencial mude o que levaria à evoluções temporais de população diferentes para diferentes campos.

Como discutimos no Capítulo 4, ainda não chegamos a uma conclusão clara sobre o que está ocorrendo nessa escala de tempo. A interpretação que estaríamos excitando ressonância moleculares explica muito bem os resultados em tempos curtos, bem como a dependência quadrática da população $(n+2) P$ em função da população em $n D$. Porém não explica o aumento da população na escala de tempo de microsegundos. 
Outra proposta para entendermos essa evolução temporal da população, descartando a hipó-tese de movimento, é imaginarmos uma evolução da função de onda que descreve o par atômico antes de sua detecção. Como a detecção é feita por um campo ionizante pulsado, o processo de detecção poderia estar sendo prejudicado dependendo da evolução temporal da função de onda eletrônica. Em outras palavras, para tempos curtos nem todos os pares existentes no sistema foram detectados devido a grande diferença da função de onda dos pares com a função de onda que descreve o estado $(n+2) P$. A medida que o tempo passa, a função de onda evoluiria para duas funções de onda atômica sem correlação e o processo de detecção se tornaria mais eficiente, consequentemente o sinal de elétrons seria maior. Tal interpretação precisa ser testada a partir de novos experimentos, pois ainda não entendemos de forma clara a mecanismo de interação.

A respeito da criação do "qubit" e avanços na área de computação quântica nosso trabalho impõe algumas restrições. Uma vez que dois estados atômicos são necessários para gerarmos o emaranhamento, o aparecimento de ressonâncias moleculares leva o sistema à decoerência e destroe o bit quântico. A mesma interação de ultra longo alcance que produz o estado emaranhado é responsável pelo aparecimento do estado molecular. Um mecanismo para evitar tal decoerência no sistema precisa ainda ser proposto.

Contudo, em trabalho recente em nosso grupo (44), foi observado fenômenos de supressão do estado $43 P$ quando o estado $41 D$ era excitado por um laser pulsado. Este efeito foi realizado graças a aplicação de radio frequência (RF). A interpretação dada é que a RF conecta os potencias $41 D+41 D$ aos potenciais repulsivos, evitando assim a transferência de população para estados mais energéticos, como o 43P. Baseado nessa evidência, futuros experimentos com átomos de Rydberg podem ser propostos, a fim de investigar em mais detalhes a eficiência dessa supressão via RF. Isto poderia consequentemente reduzir os efeitos de decoerência destas 
ressonâncias moleculares que podem destruir o "qubit".

Uma outra alternativa seria evitar que os átomos se aproximem da região de separação internuclear que permite popular tais ressonâncias, ou seja, manter os átomos fisicamente separados. Seguindo este raciocínio, estamos preparando um novo aparato experimental, cujo objetivo é isolar os átomos espacialmente sem destruir com o estado emaranhado. Para isso carregaremos uma rede óptica unidimensional a partir de uma armadilha óptica de dipolo usando um laser de $\mathrm{CO}_{2}$.

Isto fará que os átomos fiquem distribuídos em planos paralelos separados uns dos outros por $\lambda / 2=5 \mu m$. Como as ressonâncias ocorrem para separações inferiores a 1,5 4 m, este efeito não poderá ocorrer entre os planos, evitando assim a decoerência. Contudo, em um único plano este efeito ainda pode ocorrer. A solução proposta para reduzir os efeitos de decoerência no plano é justamente usar a rádio-frequência, depois claro de um estudo mais profundo a respeito de supressões.

É desta forma que os experimentos de átomos de Rydberg fios seguem daqui em diante. Já estamos iniciando a preparação de novos experimentos em nosso laboratório e acreditamos em resultados reveladores. Temos a certeza que esta área de átomos de Rydberg frios ainda está no começo, e que resultados interessantes e intrigantes ainda deverão surgir nos próximos anos. 


\section{Referências}

1 KAZANTSEV, A. P.; SURDUTOVICH, G. I.; YUKOVLEV, V. P. Mechanical action of light on atoms. Singapore: Word Scientific Publishing., 1990. 380p.

2 NASCIMENTO, V. A. Dinâmica de colisões entre átomos de Rydberg frios. 2006. $134 \mathrm{f}$. Tese (Doutorado) - Instituto de Física de Sao Carlos, Universidade de São Paulo, São Carlos, 2006.

3 RAAB, E. L. et al. Trap of neutral sodium atoms with adiation pressure. Physical Review Letters, v. 59, n. 23, p. 2631-2634, 1987.

4 WEINER, J. et al. Experiments and theory in cold and ultracold collisions. Reviews of Modern Physics., v. 71, n. 1, p. 1-85, 1999.

5 WYNANDS, R.; WEYERS, S. Atomic fountain clocks. Metrologia, v. 42, p. S64S79, 2005.

6 GILL, P. Optical frequency standards. Metrologia, v. 42, p. S125-S137, 2005.

7 FIORETTI, A. et al. Formation of cold cs2 molecules through photoassociation. Physical Review Letters, v. 80, n. 20, p. 4402-4405, 1998.

8 GABBANINI, C. et al. Cold rubidium molecules formed in a magneto-optical trap. Physical Review Letters, v. 84, n. 13, p. 2814-2817, 2000.

9 ANDERSON, M. H. et al. Observation of bose-einstein condensation in a dilute atomic vapor. Science, v. 269, n. 5221, p. 198-201, 1995.

10 DAVIS, K. et al. Bose-einstein condensation in a gas of sodium atoms. Physical Review Letters, v. 75, n. 22, p. 3969-3973, 1995.

11 BRADLEY, C. C. et al. Evidencs of bose-einstein condensation in a atoimic gas with attractive inreractions. Physical Review Letters, v. 75, n. 9, p. 1687-1690, 1995.

12 COOK, R. J. Atomic motion in resonant radiation: an application of ehenfest's theorem. Physical Review A, v. 20, n. 1, p. 224, 1979.

13 GALlAGHER, T. F. Rydberg Atoms. Cambridge: Cambridge University Press, 1994. 495p.

14 ZANON, R. A. D. S. et al. Time-resolved study of energy-transfer collisions in a sample of cold rubidium atoms. Physical Review A, v. 65, p. 023405, 2002.

15 OLIVEIRA, A. L. de et al. Rydberg cold collisions dominated by ultralong range potential. Physical Review Letters, v. 90, n. 14, p. 143002, 2003. 
16 NASCIMENTO, V. A. et al. Motion in an ultralong-range potential in cold-rydberg-atom collisions. Physical Review Letters, v. 73, p. 034703, 2006.

17 MOURACHKO, I. et al. Many-ody effects in a frozen rydberg gas. Physical Review Letters, v. 80, n. 2, p. 253-256, 1998.

18 TANNER, P. J. et al. Many-body ionization in a frozen rydberg gas. Phsical Review Letters, v. 100, p. 043002, 2008.

19 HAN, J.; GALLAGHER, T. F. Field ionization of the frozen rydberg gas. Physical Review A, v. 77, p. 015404, 2008.

20 MAGALHAES, K. M. F. et al. Lifetime determination of high excited states of 85rb using a sample of cold atoms. Optics Communications, v. 184, p. 385-389, 2000.

21 FAROOQI, S. et al. Long-range molecular resonances in a cold rydberg gas. Physical Review Letters, v. 91, n. 18, p. 183002, 2003.

22 AMTHOR, T. et al. Modeling many-particle mechanical effects of an interacting rydberg gas. Physical Review A, v. 76, p. 054702, 2007.

23 KILLIAN, T. C. et al. Formation of rydberg atoms in an expanding ultracold neutral plasma. Physical Review Letters, v. 86, n. 17, p. 3759-3762, 2001.

24 FLANNERY, M. R.; OKS, E. Plasma screening within rydberg atoms in circular states. The European Physical Journal D., v. 47, n. 1, p. 27-31, 2008.

25 DALGARNO, A. Rydberg states od atoms and molecules. Cambridge: Cambridge Universit Press, 1983.

26 JAKSCH, D. et al. Fast quantum gates for neutral atoms. Physical Review Letters, v. 85, n. 10, p. 2208-2211, 2000.

27 LUKIN, M. D. et al. Dipole blockade and quantum information processing in mesoscopic atomic ensembles. Physical Review Letters, v. 87, n. 3, p. 037901, 2001.

28 REINHARD, A. et al. Rydberg-rydberg collisions: resonant enhancement of state mixing and penning ionization. Physical Review Letters, v. 100, p. 123007, 2008.

29 FRIEBEL, S. et al. Co2-laser optical lattice with cold rubidium atoms. Physical Review A, v. 57, n. 1, p. R20-R23, 1998.

30 OVERSTREET, K. R. et al. Photoinitiated collision between cold cs ryberg atoms. Physical Review A, v. 76, p. 011403, 2007.

31 LI, W.; TANNER, P. J.; GALLAGHER, T. F. Dipole-dipole excitation and ionization in an ultracold gas of rydberg atoms. Physical Review Letters, v. 94, p. 173001, 2005.

32 ANDERSON, W. R.; VEALE, J. R.; GALLAGHER, T. F. Resonant dipole-dipole energy transfer in a nearly frozen rydberg gas. Physical Review Letters, v. 80, n. 2, p. 249-253, 1998.

33 AMTHOR, T. et al. Mechanical effect of van derwaals interactions observed in real time in an ultracold rydberg gas. Physical Review Letters, v. 98, p. 023004, 2007. 
34 CALIRI, L. L.; NASCIMENTO, V. A.; MARCASSA, L. G. Time evolution of density measurements for energy transfer collisions in a sample of cold rydberg atoms. Physical Review Letters, 2008. No prelo.

35 SINGER, K. et al. Suppression of excitation and spectral broadening induced by interactions in a cold gas of rydberg atoms. Physical Review Letters, v. 93, n. 16, p. 163001, 2004.

36 GREENE, C. H.; DICKINSON, A. S.; SADEGHPOUR, H. R. Creation of polar and nonpolar ultra-long-range rydberg molecules. Physical Review Letters, v. 85, n. 12, p. 2458-2461, 2000 .

37 BOISSEAU, C.; SIMBOTIN, I.; CôTé., R. Macrodimers: ultralong range rydberg molecules. Physical Review Letters, v. 88, n. 13, p. 133004, 2002.

38 SINGER, K. et al. Long-range interactions between alkali rydberg atom pairs correlated to the nsns, npnp and ndnd asymptotes. Journal of Physics B: Atomic, Molecular and Optical Physic, v. 38, p. S295-S307, 2005.

39 DALGARNO, A.; DAVILSON, W. D. Long-range interactions of alkali metals. Molecular Physics., v. 13, n. 5, p. 479-486, 1967.

40 ROY, R. J. L. Long-range potential coefficients from rkr turning points: $c_{6}$ and $c_{8}$ for $b\left(3 \pi_{u}^{+}\right)$. Canadian Journal of Physics, v. 52, p. 246-256, 1974.

41 MARINESCU, M. Dispersion coefficients for the np-np asymptote of homonuclear alkalimetal dimers. Physical Review A, v. 56, n. 6, p. 4764-4773, 1997.

42 SCHWETTMANN, A. et al. Cold cs rydberg-gas interactions. Physical Review A, v. 74, p. 020701(R), 2006.

43 GALLAGHER, T. F. Rydberg atoms. Reports on Progress in Physics, v. 51, p. 143-188, 1988.

44 CALIRI, L. L. Processo binário em átomos de Rydberg. 2006. 75p. Dissertação (Mestrado) — Instiuto de Física de Sao Carlos, Universidade de São Paulo, São Carlos, 2006.

45 CALIRI, L. L.; NASCIMENTO, V. A.; MARCASSA, L. G. Time evolution of density measurements for energy transfer collisions in a sample of cold rydberg atoms. Physical Review Letters, 2007. No prelo.

46 YARIV, A. Quantum electronics. New York: Wiley, 1967. 495p.

47 FOWLES, G. R. Introduction to modern optics. New York: Dover Publications, 1989. 